\title{
The distributionally robust newsvendor problem with dual sourcing under carbon tax and cap-and-trade regulations
}

\begin{abstract}
Both carbon tax and cap-and-trade regulations as carbon emissions reduction schemes are widely adopted and implemented in practice. Based on the dual souricng newsvendor framework, this paper proposes two distributionally robust newsvendor models under those two carbon regulations. The optimal order quantity and carbon emissions of each model are derived by using a maximin expected profit method, and comparisons of the profits between the models with and without carbon emission regulations are provided. It is observed that the carbon tax regulation will lead to a lower profit while adjusting the value of carbon cap leads to comparable profits between the model under cap-and-trade regulation and that without carbon emission consideration. Finally, several numerical examples are presented to illustrate the analytical results and the models developed herein.
\end{abstract}

Keywords: Carbon emission, newsvendor, distributionally robust, carbon tax, cap-and-trade

\section{Introduction}

Reducing carbon dioxide $\left(\mathrm{CO}_{2}\right)$ and other greenhouse gas emissions has become a public consensus around the globe in recent years. There are many reports and scientific studies indicating that, if left unchecked, these gases will lead to major changes in the earth's climate system. Under growing public pressure, many national and international authorities have enacted legislations or designed mechanisms to curb these emissions. Cap-and-trade (also called emissions trading system) and carbon tax are widely adopted and implemented in practice. Under the cap-and-trade regulation, a firm is allocated a predetermined amount of carbon emissions (a carbon cap) by a government agency. If the firm's actual amount of carbon emissions exceeds the carbon cap, it can buy carbon emission permits on a carbon trading market such as the European Emissions Trading System (EU ETS). If a firm's actual amount of carbon emissions is less than the cap, the firm can sell its surplus emission permits on the same market. Currently, there are more than 20 platforms for carbon trading in the world with the EU ETS being the largest. Under the carbon tax regulation, a firm is charged for its carbon emissions through taxes. According to a recent report by the World Bank (2014), 14 countries have implemented carbon taxes. Because these two regulation schemes have different effects on operational decisions of a firm, many researchers, e.g., Avi-Yonah \& Uhlmann (2009) and He et al. (2012), have studied this issue and compared the effects of cap-and-trade and carbon tax regulations.

Consequently, many manufacturing and service companies, as the primary sources of carbon emissions, have been searching for a more balanced strategy for maximum profits, better customer service and minimum carbon emission. Dual sourcing approach in supply chain management is one of the quick response systems and has been proposed to cope with uncertain market demand. From Warburton \& Stratton (2005) and Rosič \& Jammernegg (2013), dual sourcing means that in a supply chain system, a retailer has two supply sources. The first supplier is cost-efficient and has long replenishment lead time while the second one is more expensive but can deliver on short notice. Moreover, the first supplier can be an offshore supplier which is usually far away from the market. Products from the offshore supplier may lead to high carbon emissions due to transportation or less sophisticated production technology, or both. The second supplier can be an onshore supplier located close to the market and generates low carbon emissions, but charges higher price for the same product. In this system, the retailer first orders products from the offshore supplier to meet the demand. Once the demand exceeds the ordered quantity, the onshore supplier is used to satisfy the remaining demand timely. In addition, those two supply sources may also be a single supplier with two ordering possibilities. This system is quite popular in certain industries such as fashion apparel (Choi, 2013; Rosič \& Jammernegg, 2013). On 
the other hand, market demand is volatile and its distributional information may not be always available (Kunmar \& Goswami, 2015). It is more challenging for the retailer to make the right decisions under different carbon regulations.

To address the dual sourcing decision problem under different carbon emission regulations, in this paper we consider a newsvendor problem with dual sourcing under carbon tax and cap-and-trade regulations. We propose two distributionally robust optimization models assuming that carbon emissions are associated with product ordering and storing. We also assume that the demand distribution information is limited to the mean and variance. To maximize the expected profit against the worst possible distribution of the demand, we use the maximin approach to solve the models developed in this paper. Finally, several numerical examples are presented to illustrate these models and the analytical results.

The main contributions of this paper are as follows. First, this paper incorporates carbon footprint into the newsvendor problem with dual sourcing and constructs two distributionally robust newsvendor models under carbon tax and cap-and-trade regulations. Second, this paper adopts a maximin method to obtain the optimal order quantity so that the effects of uncertain demand can be reduced. Specifically, under carbon tax regulation, we prove that zero order quantity from the offshore supplier can be profitable. Under cap-and-trade regulation, we consider that the emission permits buying and selling prices of the retailer can be different and develop closed form expressions of the optimal order quantity to provide in depth analysis on how uncertainty can affect the solutions of newsvendor problem. Finally, under the two carbon regulations, two newsvendor models with dual sourcing are analyzed and compared regarding ordering time and quantities from offshore and onshore sources. The developed models and analytical results from this research would be useful for authorities in setting up carbon cap limits or tax rates if real industry data are used.

The remainder of this paper is organized as follows. Section 2 reviews related literature. Section 3 describes the problem in more detail and introduces notations used in modeling the problem. In Section 4, we formulate two distributionally robust newsvendor models with dual sourcing under carbon tax and cap-and-trade regulations. We also solve the models to optimality and compare the profits from these two models with that without considering carbon emission. Section 5 presents numerical examples to illustrate the models and the analytical results. Conclusions are presented in Section 6.

\section{Literature review}

The classical newsvendor problem, also called the single-period stochastic inventory problem, has attracted considerable attention in the past decades and there exists a large body of literature. Here, we limit this review to the works closely related to the models and methods used in this paper.

\subsection{The newsvendor problem with dual sourcing under carbon emission regulations}

The newsvendor problems with different carbon emission regulations have been widely discussed in recent years due to growing environmental considerations. Song \& Leng (2012) considered a mandatory carbon emission capacity, a carbon emission tax and a cap-and-trade regulation system, and investigated the single-period newsvendor problem under each carbon emission regulation. Assuming that carbon emissions are generated from product ordering, they derived optimal order policy under each carbon emission regulation, and provided insightful analysis on the effect of each regulation on expected profits. Zhang \& Xu (2013) considered a single-period and multi-item newsvendor problem with cap-and-trade regulation. They derived optimal order policy to maximize total expected profit and proposed a simple solution method with linear computational complexity. Manikas \& Kroes (2015) considered a multi-period newsvendor problem under the cap-and-trade regulation, and applied a forward buying algorithm to determine the number of time periods to buy permits, the current production level, and the required current and future emissions permits. In addition to the above mentioned work focusing on solving optimal order policy for individual firms, there are several papers addressing supply chain coordination problems under different carbon emission regulations based on newsvendor framework. Recent publications include Du et al. (2011), Du et al. (2013), Dong et al. (2014), among others.

In a single source newsvendor problem, typically a retailer orders from a certain supply source and has a oneordering policy to satisfy the uncertain market demand. In such systems, unsatisfied demand is usually lost and financial losses incur when demand exceeds the order quantity. The retailer may need an emergency supply source to 
satisfy the unforeseen demand. Newsvendor models with dual sourcing as an extension to the classical newsvendor model have been proposed and widely discussed in literature. Khouja (1996) considered a newsvendor problem with an emergency supply option assuming that a fixed fraction of the shortage can be satisfied by the second ordering after demand realization. Warburton \& Stratton (2005) developed a dual sourcing newsvendor model with an onshore and an offshore supplier. In their model, the offshore supplier has a low-cost and long lead time while the onshore supplier has a high-cost and is located close to the market. The onshore supplier is a backup to fulfil the remaining demand. Oberlaender (2011) incorporated different risk preferences into a newsvendor model with dual sourcing, and derived optimal order quantity to maximize expected utility of profit. Pando et al. (2013) derived a closed-form expression of optimal order quantity for newsvendor problem with dual sourcing. They assumed that a variable fraction of the shortage can be satisfied with emergency order from the second supplier. Choi (2013) considered a newsvendor model with dual sourcing and developed a quick response system under carbon tax regulation. Assuming that the second order is placed based on a forecast update, the author illustrated how the carbon tax regulation affects the optimal choice of sourcing decision. Considering environment impact of transport, Rosič \& Jammernegg (2013) investigated the newsvendor problem with dual sourcing under carbon tax and cap-and-trade regulations. Assuming that carbon emissions are directly related to the offshore order quantity, they derived optimal order quantity and showed that dual sourcing can have less transport emissions comparing to a single offshore sourcing strategy. Arikan \& Jammernegg (2014) further considered a newsvendor problem with dual sourcing under carbon cap regulation. They derived the optimal production policy and obtained some managerial insights with a sensitivity analysis.

In the above-mentioned models, probability distributions of the market demand are assumed to be known. However, in solving real world problems, it is often difficult to completely characterize market demand, especially with limited historical data or less accurate forecast methods. In the following section, we will analyze the impact of carbon regulations on distributionally robust newsvendor problems with dual sourcing.

\subsection{The distributionally robust newsvendor problem}

Distributionally robust newsvendor problems have received considerable attention since Scarf (1958) established the robust newsvendor model and derived an analytical expression for optimal order quantity that maximizes the expected profit against the worst possible distribution of the demand with known mean and variance. Gallego \& Moon (1993) obtained the same results with a more concise proof using Cauchy-Schwartz inequality. Alfares \& Elmorra (2005) extended the distributionally robust newsvendor model to the case that a shortage penalty cost is considered. Other extensions of this model can be found in Moon \& Choi (1995), Ouyang \& Chang (2002), Mostard et al. (2005), Kevork (2010), among others.

More recently, Liao et al. (2011) incorporated a linear penalty cost for lost sales into the distributionally robust newsvendor model with balking, and developed a procedure for deriving the optimal order policy. Lee \& Hsu (2011) considered the effect of advertising on distributionally robust newsvendor model and constructed three cases of demand variations as a function of advertising expenditure. These authors provided the closed-form solutions of optimal expenditure on advertising and optimal order quantity to maximize expected profit. Later, Güray Güler (2014) made further analysis on this problem. Kamburowski (2014) considered distributionally robust newsvendor problems under best-case and worst-case scenarios, and derived some new theoretical results. Han et al. (2014) adopted a risk- and ambiguity-averse approach to analyze this problem, and derived a closed form order formula, a generalization of the Scarf order formula. Liu et al. (2015) considered a independent remanufacturers (IRs) system under mandatory carbon emission capacity, carbon tax and carbon cap-and-trade regulations, and constructed three distributionally robust newsvendor models to determine the remanufacturing quantity that maximizes the total profits. Recently, distributionally robust newsvendor problems based on minimax regret or maximum entropy approach were studied. Examples are Yue et al. (2006), Perakis \& Roels (2008), Lan et al. (2011), Andersson et al. (2013), Zhu et al. (2013).

One of the main characteristics of the above-mentioned models is that a single suppler is used to satisfy the demand without considering the effects of carbon emission. In this paper, we will incorporate carbon footprint into the distributionally robust newsvendor problem with dual sourcing and solve the constructed models analytically and numerically. 


\section{Model Framework}

We consider a dual sourcing model where a retailer facing stochastic demand $d$ has two ordering possibilities such that an emergency order will be placed to satisfy unfilled demand during high season. The first supply source, an offshore supplier, usually has a long lead time and low cost and is inflexible. The second supply source is an onshore supplier and offers a fast and flexible service with higher cost. The onshore supplier is considered to be as a backup of the offshore supplier. To meet the market demand $d$, the retailer orders $q$ amount of products with unit cost $c$ from the offshore supplier. If $q \geq d$, the unsold products can be salvaged at unit price $v$. Otherwise, (i.e., $q<d$ ), the retailer immediately orders $d-q$ units with unit cost $c+a(a>0)$ from the onshore supplier to meet the market demand. Moreover, we assume that the cumulative distribution $F$ of $d$ belongs to a class $\Psi$ of functions with mean $\mu$ and variance $\sigma^{2}$. This process of the stated problem is illustrated in Figure 1.

*******************************************************************************************

$* * * * * * * * * * * * * * * * * * * * * * * * * *$ Please insert Figure 1. $* * * * * * * * * * * * * * * * * * * * * * * * * * * * *$

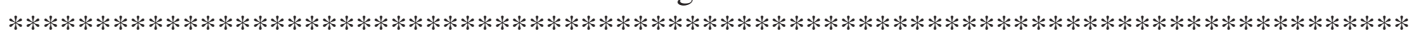

Let the unit selling price $p$ be exogenous following the classical newsvendor model. Without loss of generality, it is assumed that $p>c>v$. In the considered problem, we assume that the unit ordering cost from the onshore supplier $c+a$ is higher than the sum of the unit ordering cost from the offshore supplier $c$ and the unit cost of overstocking $c-v$, i.e., $c+a>2 c-v$ or $a>c-v$. Then, the total expected profit of the retailer is expressed as

$$
\Pi_{0}(q)=E\left\{p d+v(q-d)^{+}-c q-(c+a)(d-q)^{+}\right\},
$$

where $x^{+}=\max \{x, 0\}$. The total expected profit of the retailer in Eq.(1) consists of the income from selling the product, the salvage income from excess order, and the first and second order costs.

Since carbon emissions can be generated from the ordering and storing process, we incorporate carbon emissions associated with the first order from the offshore supplier, the inventory level and the second order from the onshore supplier into our model development. Let $e_{1}, e_{2}$ and $e_{3}$ denote the amount of carbon emissions per unit generated from the first order, the unsold product and the second order, respectively. Then the total expected emission level in the dual sourcing operation can be expressed as

$$
C(q)=E\left\{e_{1} q+e_{2}(q-d)^{+}+e_{3}(d-q)^{+}\right\} .
$$

As discussed earlier, it is assumed that $e_{1}>e_{3}$. Using $(q-d)^{+}=q-d+(d-q)^{+}$, we simplify Eqs.(1) and (2), respectively, as

$$
\Pi_{0}(q)=(p-v) \mu-(c-v) q-(c+a-v) E(d-q)^{+}
$$

and

$$
C(q)=\left(e_{1}+e_{2}\right) q-e_{2} \mu+\left(e_{2}+e_{3}\right) E(d-q)^{+} .
$$

The notations used in the above equations and the remaining part of the paper are summarized in Table 1. Additional notations and assumptions will be listed when needed.

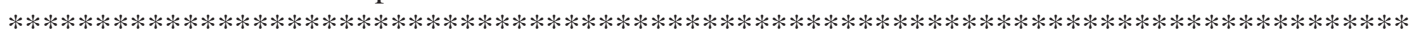

****************************** Please insert Table 1. $* * * * * * * * * * * * * * * * * * * * * * * * * * * * *$

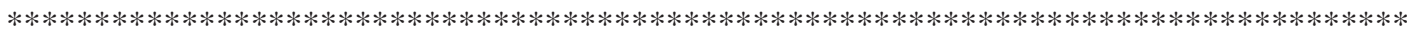

\section{Mathematical models under carbon tax and carbon cap-and-trade regulations}

In this section, we investigate the dual sourcing problem under carbon tax and cap-and-trade regulations by formulating two distributionally robust newsvendor models. All proofs of analytical results can be found in the appendices of this paper. 


\subsection{Carbon tax regulation}

Under carbon tax regulation, the retailer is charged for each unit of carbon emission with a financial penalty, i.e., a tax $c_{t}$. The objective of the retailer is to determine the optimal order quantity from the offshore supplier to maximize its profit. From Eqs.(1) and (2), we know that the uncertainty of the market demand affects not only the profit but also the amount of carbon emissions. Since mean $\mu$ and variance $\sigma^{2}$ of the demand distribution are known, we can use the distributionally robust approach to determine the optimal order quantity, which maximizes the expected profit against the worst possible distribution of the demand. The distributionally robust newsvendor model with dual sourcing under carbon tax regulation can be formulated as

$$
\begin{aligned}
& \left(P_{1}\right) \quad \max _{q} \min _{F \in \Psi} \Pi_{1}(q) \\
& \text { s.t } \quad q \geq 0
\end{aligned}
$$

where $\Pi_{1}(q)=\Pi_{0}(q)-c_{t} C(q)$.

To solve $P_{1}$, we first present the following Lemma from Gallego \& Moon (1993).

Lemma 4.1. $E(d-q)^{+} \leq \frac{\left[\sigma^{2}+(q-\mu)^{2}\right]^{\frac{1}{2}}-(q-\mu)}{2}$ holds for the demand distribution with given mean $\mu$ and variance $\sigma^{2}$. Moreover, there exists a two-point distribution such that the upper bound is tight.

If we let $c_{t}=0$ in Eq.(5), $P_{1}$ reduces to $P_{0}$, which is a distributionally robust dual sourcing newsvendor problem without carbon emission consideration. Let $\Pi_{0}^{F}(q)$ be the expected profit of $P_{0}$ under the worst distribution of demand $\min _{F \in \Psi} \Pi_{0}(q)$, and $q_{0}^{*}$ be the corresponding optimal robust order quantity. Using Eq.(3) and Lemma 4.1, we have the optimal order quantity and the corresponding profit of problem $P_{0}$ as

$$
q_{0}^{*}=\mu+\frac{\sigma}{2}\left[\left(\frac{a}{c-v}\right)^{\frac{1}{2}}-\left(\frac{c-v}{a}\right)^{\frac{1}{2}}\right]
$$

and

$$
\Pi_{0}^{F}\left(q_{0}^{*}\right)=(p-c) \mu-\sigma(c-v)^{\frac{1}{2}} a^{\frac{1}{2}} .
$$

With the assumption that $a>c-v$, we easily obtain $q_{0}^{*}>0$ which implies that the retailer usually orders certain amount of products from the offshore supplier when carbon emissions are not considered in the process.

Let $C^{F}(q)$ be $\max _{F \in \Psi} C(q)$. From Eq.(4) and Lemma 4.1, we have

$$
C^{F}(q)=\left(e_{1}+e_{2}\right) q-e_{2} \mu+\left(e_{2}+e_{3}\right) \frac{\left\{\left[\sigma^{2}+(q-\mu)^{2}\right]^{\frac{1}{2}}-(q-\mu)\right\}}{2} .
$$

We have the following conclusion on the function $C^{F}(q)$.

Lemma 4.2. $C^{F}(q)$ is a positive increasing convex function of $q$.

Proof. Please see Appendix A.

Let $\Pi_{1}^{F}(q)$ be $\min _{F \in \Psi} \Pi_{1}(q)$, and $q_{1}^{*}$ be the optimal order quantity in solving $P_{1}$. Substituting Eqs.(3) and (4) into Eq.(5), and using Lemma 4.1, we have

$$
\Pi_{1}^{F}(q)=\left(p-v+c_{t} e_{2}\right) \mu-\left[c+a-v+c_{t}\left(e_{2}+e_{3}\right)\right] \frac{\left\{\left[\sigma^{2}+(q-\mu)^{2}\right]^{\frac{1}{2}}-(q-\mu)\right\}}{2}-\left[c+c_{t}\left(e_{1}+e_{2}\right)-v\right] q .
$$

From Eqs.(9) and (10), it is easy to conclude with Lemma 4.1 that there exists a two-point distribution such that $\max _{F \in \Psi} C(q)$ and $\min _{F \in \Psi} \Pi_{1}(q)$ hold. By analyzing the optimal property of Eq.(10), we further have the following conclusion. 
Theorem 4.3. For problem $P_{1}$, there exists a threshold $q_{t}$ such that $q_{1}^{*}=\max \left\{q_{t}, 0\right\}$, where

$$
q_{t}=\mu+\frac{\sigma}{2}\left(\sqrt{\frac{A_{1}}{B_{1}}}-\sqrt{\frac{B_{1}}{A_{1}}}\right)
$$

$A_{1}=a-c_{t} e_{1}+c_{t} e_{3}$ and $B_{1}=c-v+c_{t} e_{1}+c_{t} e_{2}$.

Proof. Please see Appendix B.

We note that $a>c_{t}\left(e_{1}-e_{3}\right)$ will guarantee the feasibility of $q_{t}$ in Eq.(11). From Theorem 4.3, we observe that the retailer may decide not to order from the offshore supplier when carbon tax is imposed and market demand will be met by the onshore supplier.

Let $A_{2}=p-c-a-c_{t} e_{3}$ and $B_{2}=p-v+c_{t} e_{2} . A_{2}$ should be positive since selling price should be higher than the total cost including order cost and carbon emission tax. Following Theorem 4.3, we obtain the following conclusion.

Corollary 4.4. For problem $P_{1}$, the following hold for $B_{1}>A_{1}$ :

(i) When $\frac{\sigma}{\mu}>\frac{2 \sqrt{A_{1} B_{1}}}{B_{1}-A_{1}}$, the retailer will order d products from the onshore supplier which leads to a positive expected profit as $A_{1} B_{2}<A_{2} B_{1}$ and $\frac{\sigma}{\mu}<\frac{2 \sqrt{A_{2} B_{2}}}{B_{2}-A_{2}}$.

(ii) When $\frac{\sigma}{\mu}>\frac{2 \sqrt{A_{1} B_{1}}}{B_{1}-A_{1}}$, the retailer will order d products from the onshore supplier which leads to a non-positive expected profit as $A_{1} B_{2} \geq A_{2} B_{1}$ or $A_{1} B_{2}<A_{2} B_{1}$ and $\frac{\sigma}{\mu} \geq \frac{2 \sqrt{A_{2} B_{2}}}{B_{2}-A_{2}}$.

(iii) When $\frac{\sigma}{\mu} \leq \frac{2 \sqrt{A_{1} B_{1}}}{B_{1}-A_{1}}$, the retailer will order $q_{t}$ products from the offshore supplier which leads to a positive expected profit as $p>c+c_{t} e_{1}+\frac{2 A_{1} B_{1}}{B_{1}-A_{1}}$.

Proof. Please see Appendix C.

Corollary 4.4 summarizes the order quantities and profits of the retailer under different conditions. In many practical situations, the bullwhip effect leads to a higher value of the coefficient of variation $(\mathrm{CV})$, or $\frac{\sigma}{\mu}$, of the demand distribution and the retailer has to make decisions with additional risk. For example, when the value of CV is higher than $\frac{2 \sqrt{A_{1} B_{1}}}{B_{1}-A_{1}}$, the retailer will order from the onshore supplier only to avoid the negative effect of the risk. Corollary 4.4 (i) shows that the retailer can have a positive expected profit with zero order quantity from the offshore supplier. On the other hand, Corollary 4.4 (ii) shows that zero order quantity policy can also result in a negative expected profit due to higher $C V$ value and higher risk. When the value of $C V$ is lower than $\frac{2 \sqrt{A_{1} B_{1}}}{B_{1}-A_{1}}$, the retailer will order $q_{t}$ products from the offshore supplier. Corollary 4.4 (iii) states that a positive expected profit can be obtained by nonzero order quantity when the selling price is higher than $c+c_{t} e_{1}+\frac{2 A_{1} B_{1}}{B_{1}-A_{1}}$

Corollary 4.5. For problem $P_{1}$ with $B_{1} \leq A_{1}$, the retailer will order $q_{t}$ products from the offshore supplier. Moreover, if $\frac{\sigma}{\mu}<\frac{p-c-c_{l} e_{1}}{\sqrt{A_{1} B_{1}}}$, then the expected profit for the retailer will be positive. Otherwise, the expected profit will be less than or equal to zero.

Corollary 4.5 is intuitive. From $B_{1} \leq A_{1}$, we obtain $a \geq c-v+c_{t}\left(2 e_{1}+e_{2}-e_{3}\right)$ which implies that the unit order cost from the onshore supplier is at least $c-v+c_{t}\left(2 e_{1}+e_{2}-e_{3}\right)$ higher than that from the offshore supplier. Corollary 4.5 implies that the retailer can obtain a positive expected profit with lower risk by ordering $q_{t}$ products from the offshore supplier when the value of $\mathrm{CV}$ is less than $\frac{p-c-c_{\ell} e_{1}}{\sqrt{A_{1} B_{1}}}$.

We further analyze the effects of carbon emission tax on the total optimal profit of problem $P_{1}$ and the corresponding carbon emissions. We have the following observation.

Theorem 4.6. $\Pi_{1}^{F}\left(q_{1}^{*}\right)$ is a decreasing and convex function of $c_{t}$ and $C^{F}\left(q_{1}^{*}\right)$ is a non-increasing function of $c_{t}$.

Proof. Please see Appendix D.

Theorem 4.6 states that as carbon tax $c_{t}$ increases, profit for the retailer will decrease while carbon emission will not increase.

Comparing problems $P_{1}$ and $P_{0}$, we have the following conclusion.

Theorem 4.7. For problems $P_{1}$ and $P_{0}$, we have $q_{1}^{*}<q_{0}^{*}$ and $\Pi_{1}^{F}\left(q_{1}^{*}\right)<\Pi_{0}^{F}\left(q_{0}^{*}\right)$.

Proof. Please see Appendix E.

Theorem 4.7 states that imposing carbon tax will reduce order quantity and profit for the retailer. This is also consistent with practical situation that carbon tax is imposed to effectively control carbon emission. 


\subsection{Cap-and-trade regulation}

Under the cap-and-trade regulation, the retailer first receives a permit for carbon emission at a certain level, i.e., a cap $K$. If the actual emission level is lower than $K$, the retailer can sell the unused amount on the carbon market at unit price $c_{s}$. If it is higher than $K$, the retailer needs to buy extra permit at unit price $c_{b}$. With the widely used assumption that the buying price is higher than the selling price of the carbon emission permit, i.e., $c_{b} \geq c_{s}$ (e.g., Song \& Leng, 2012; Gong \& Zhou, 2013), the distributionally robust newsvendor model with dual sourcing under cap-and-trade regulation can be formulated as

$$
\begin{gathered}
\left(P_{2}\right) \quad \max _{q} \min _{F \in \Psi} \Pi_{2}(q) \\
\text { s.t } \quad q \geq 0
\end{gathered}
$$

where $\Pi_{2}(q)=\Pi_{0}(q)+c_{s}(K-C(q))^{+}-c_{b}(C(q)-K)^{+}$and $x^{+}=\max \{x, 0\}$.

Problem $P_{2}$ shows that the uncertainty of the market demand affects the total profit and the carbon emissions. Bertsimas \& Thiele (2006) pointed out that robust optimization addresses the problem of data uncertainty by guaranteeing the feasibility and optimality of solution for the worst instances of the parameters. In that regard, we replace the uncertain value in $C(q)$ by its worst-case value, i.e., $\max _{F \in \Psi} C(q)$, for robustness purpose. Hence, when $C(q) \leq K$, problem $P_{2}$ becomes

$$
\begin{gathered}
\left(P_{21}\right) \quad \max _{q} \min _{F \in \Psi} \Pi_{21}(q)=\Pi_{0}(q)+c_{s}[K-C(q)] \\
\text { s.t } \max _{F \in \Psi} C(q) \leq K \\
q \geq 0
\end{gathered}
$$

From Lemma 4.1, and following Eqs.(3), (4) and (14), we can observe that there exists a two-point distribution such that $\Pi_{21}(q)$ can be minimized as $C(q)$ is maximized. Then by solving problem $P_{21}$, we can derive the optimal order quantity against the worst possible distribution of the demand with carbon emissions not exceeding $K$.

On the other hand, if $C(q) \geq K$, problem $P_{2}$ becomes

$$
\begin{gathered}
\left(P_{22}\right) \quad \max _{q} \min _{F \in \Psi} \Pi_{22}(q)=\Pi_{0}(q)-c_{b}[C(q)-K] \\
\text { s.t } \max _{F \in \Psi} C(q) \geq K \\
q \geq 0
\end{gathered}
$$

From Eq.(9) and Lemma 4.2, when the retailer does not order product from the offshore supplier and the market demand is fully satisfied by the onshore supplier, the minimum carbon emission will be $\frac{\left(e_{3}-e_{2}\right) \mu+\left(e_{2}+e_{3}\right) \sqrt{\mu^{2}+\sigma^{2}}}{2}$. Consequently, in the remainder, we assume $K \geq \frac{\left(e_{3}-e_{2}\right) \mu+\left(e_{2}+e_{3}\right) \sqrt{\mu^{2}+\sigma^{2}}}{2}$. The result shown in the following Lemma can be used to solve $P_{21}$ and $P_{22}$.

Lemma 4.8. When $K \geq \frac{\left(e_{3}-e_{2}\right) \mu+\left(e_{2}+e_{3}\right) \sqrt{\mu^{2}+\sigma^{2}}}{2}$, there exists a unique solution $q_{c 1} \geq 0$ such that $C^{F}(q)=K$, where

$$
q_{c 1}=\frac{2 K\left(2 e_{1}+e_{2}-e_{3}\right)+2 \mu\left(e_{1} e_{2}-e_{1} e_{3}-2 e_{2} e_{3}\right)-\left(e_{2}+e_{3}\right) \sqrt{\Delta}}{4\left(e_{1}+e_{2}\right)\left(e_{1}-e_{3}\right)}
$$

and $\Delta=4\left[\left(K-e_{1} \mu\right)^{2}+\left(e_{1}+e_{2}\right)\left(e_{1}-e_{3}\right) \sigma^{2}\right]$.

Proof. Please see Appendix F.

Let $\Pi_{21}^{F}(q)$ be $\min _{F \in \Psi} \Pi_{21}(q)$ and $q_{21}^{*}$ be the optimal order quantities in solving problem $P_{21}$. Using Lemmas 4.2 and 4.8 , we have the following conclusion.

Theorem 4.9. For problem $P_{21}$, there exists a unique optimal solution $q_{21}^{*}$ such that $q_{21}^{*}=\min \left\{\max \left\{q_{21}, 0\right\}, q_{c 1}\right\}$ and the expected profit of the retailer is maximized, where,

$$
q_{21}=\mu+\frac{\sigma}{2}\left(\sqrt{\frac{A_{3}}{B_{3}}}-\sqrt{\frac{B_{3}}{A_{3}}}\right),
$$

$A_{3}=a-c_{s}\left(e_{1}-e_{3}\right)$ and $B_{3}=c-v+c_{s}\left(e_{1}+e_{2}\right)$. 
Proof. Please see Appendix G.

We note that $a>c_{b}\left(e_{1}-e_{3}\right)$ will guarantee the feasibility of the model under the cap-and-trade regulation. With the assumption that $c_{b} \geq c_{s}$ and $c>v$, we have $A_{3}>0$ and $B_{3}>0$. From Theorem 4.9, we can conclude that when the carbon emission does not exceed the cap, the retailer will order $q_{c 1}$ products from the offshore supplier to reach the carbon cap $K$. If the order quantity is less than $q_{c 1}$, the carbon emission level will be lower than $K$.

From Theorem 4.9, we can obtain the following observations.

Corollary 4.10. For problem $P_{21}$, the following hold:

(i) When $B_{3} \leq A_{3}$ or $B_{3}>A_{3}$ and $\frac{\sigma}{\mu}<\frac{2 \sqrt{A_{3} B_{3}}}{B_{3}-A_{3}}$, the retailer will order $\min \left\{q_{21}, q_{c 1}\right\}$ products from the offshore supplier. Moreover, if $q_{21}>q_{c 1}$, then $\Pi_{21}^{F}\left(q_{21}^{*}\right)<\Pi_{0}^{F}\left(q_{0}^{*}\right)$. Otherwise, $\Pi_{21}^{F}\left(q_{21}^{*}\right) \geq \Pi_{0}^{F}\left(q_{0}^{*}\right)$ holds for $K>C^{F}\left(q_{0}^{*}\right)$.

(ii) When $B_{3}>A_{3}$ and $\frac{\sigma}{\mu} \geq \frac{2 \sqrt{A_{3} B_{3}}}{B_{3}-A_{3}}$, the retailer will order d products from the onshore supplier which leads to a positive expected profit as $K>K_{L}$, where $K_{L}=\frac{1}{2 c_{s}}\left\{\left[c+a-v+c_{s}\left(e_{2}+e_{3}\right)\right]\left(\sigma^{2}+\mu^{2}\right)^{\frac{1}{2}}-\left[2 p-v-c-a+c_{s}\left(e_{2}-e_{3}\right)\right] \mu\right\}$.

Proof. Please see Appendix H.

Corollary 4.10 (i) indicates that the retailer is willing to order from the offshore supplier when the following conditions occur: $a \geq c-v+c_{s}\left(2 e_{1}+e_{2}-e_{3}\right)$ or $a<c-v+c_{s}\left(2 e_{1}+e_{2}-e_{3}\right)$ and $\frac{\sigma}{\mu}<\frac{2 \sqrt{A_{3} B_{3}}}{B_{3}-A_{3}}$. The first condition shows that the unit order cost from the offshore supplier is lower by $c-v+c_{s}\left(2 e_{1}+e_{2}-e_{3}\right)$ than its onshore counterpart while the second condition shows that the influence of uncertainty information on the market demand is limit. Under this scenario, the retailer will have less profit than the case without carbon emission consideration when the carbon emission level is equal to $K$. On the other hand, the retailer may have more profit if $K$ is higher than $C^{F}\left(q_{0}\right)$. This flexibility on profit can also explain why cap-and-trade is a popular mechanism in practice. Corollary 4.10 (ii) means that the market demand will be fully satisfied by the onshore supplier when the value of CV is higher than or equal to $\frac{2 \sqrt{A_{3} B_{3}}}{B_{3}-A_{3}}$, indicating higher demand uncertainty. If the value of $K$ is higher than $K_{L}$, profit of the retailer will be positive..

With similar analysis, we have the following conclusion for problem $P_{22}$.

Theorem 4.11. For problem $P_{22}$, there exists a unique optimal solution $q_{22}^{*}$ such that $q_{22}^{*}=\max \left\{q_{22}, q_{c 1}\right\}$ and the expected profit of the retailer is maximized, where,

$$
q_{22}=\mu+\frac{\sigma}{2}\left(\sqrt{\frac{A_{4}}{B_{4}}}-\sqrt{\frac{B_{4}}{A_{4}}}\right)
$$

$A_{4}=a-c_{b}\left(e_{1}-e_{3}\right)>0$ and $B_{4}=c-v+c_{b}\left(e_{1}+e_{2}\right)>0$.

Using similar method in solving Eq.(21), we can derive Eq. (22) without much difficulty. So we omit the detailed proof of Theorem 4.11. From Theorem 4.11, we conclude that when $q_{22}>q_{c 1}$, the retailer will order $q_{22}$ products from the offshore supplier and the carbon emission level will be higher than $K$. Moreover, the carbon emissions generated by ordering $q_{c 1}$ products are equal to $K$.

From Theorem 4.11, we have the following conclusion.

Corollary 4.12. When the carbon emission level is higher than or equal to $K$, the expected profit of the retailer is always less than that without carbon emission consideration, i.e., $\Pi_{22}^{F}\left(q_{22}^{*}\right)<\Pi_{0}^{F}\left(q_{0}^{*}\right)$.

Corollary 4.12 can be obtained by using the fact that $q_{22}^{*}$ and $q_{0}^{*}$ are the feasible and optimal solutions of the model without carbon emissions consideration. Corollary 4.12 indicates that cap-and-trade regulation will reduce the retailer's profit under certain conditions. The reduced profit can be viewed as a penalty for having higher than allowable emissions. Under this scenario, the government should strengthen the supervision to guarantee the effectiveness of the cap-and-trade regulation.

Let $\Pi_{2}^{F}(q)$ be the value of $\min _{F \in \Psi} \Pi_{2}(q)$ and $q_{2}^{*}$ be the optimal order quantity of problem $P_{2}$. From Theorems 4.9 and 4.11, we have the following conclusion. 
Theorem 4.13. In solving problems $P_{21}$ and $P_{22}$, we have $q_{21}^{*} \leq q_{22}^{*}$. Moreover, the optimal order quantity of problem $P_{2}$ is given by

$$
q_{2}^{*}= \begin{cases}q_{21}^{*}, & \Pi_{21}^{F}\left(q_{21}^{*}\right) \geq \Pi_{22}^{F}\left(q_{22}^{*}\right), \\ q_{22}^{*}, & \Pi_{21}^{F}\left(q_{21}^{*}\right) \leq \Pi_{22}^{F}\left(q_{22}^{*}\right) .\end{cases}
$$

Proof. Please see Appendix I.

In order to obtain a fair comparison between carbon tax and cap-and-trade regulations, from Theorem 4.7 and Corollary 4.10(i), we have the following observation.

Corollary 4.14. When the carbon cap $K$ satisfies $K>C^{F}\left(q_{0}^{*}\right)$, the expected profit of the retailer under cap-and-trade regulation is more than that under carbon tax regulation, i.e., $\Pi_{1}^{F}\left(q_{1}^{*}\right)<\Pi_{2}^{F}\left(q_{2}^{*}\right)$.

Corollary 4.14 is intuitive. Corollary 4.14 indicates that cap-and-trade regulation is preferred to carbon tax regulation as the retailer may have higher profit. This is one of the main reasons that cap-and-trade is a popular regulating scheme in practice.

\section{Numerical example}

To illustrate the above analytical results as well as to gain some managerial insights, we perform numerical analysis in this section. Parameter values used in this example are $p=60, c=10, v=5, a=18, c_{t}=3.2, c_{b}=3.2, c_{s}=2, e_{1}=$ $5, e_{2}=3, e_{3}=1, \mu=800, \sigma=196$ and $K=5000$.

The optimal order quantities and corresponding profits in solving problems $P_{1}$ and $P_{2}$ are, respectively, $q_{1}^{*}=$ 602.67 and $\Pi_{1}^{F}\left(q_{1}^{*}\right)=2.4728 \times 10^{4}$; as well as $q_{2}^{*}=725.61$ and $\Pi_{2}^{F}\left(q_{2}^{*}\right)=3.916 \times 10^{4}$. The corresponding carbon emission levels under carbon tax and cap-and-trade regulations are $C^{F}\left(q_{1}^{*}\right)=3372.3$ and $C^{F}\left(q_{2}^{*}\right)=3972.9$ respectively. From above computational results, we easily have that $q_{2}^{*}>q_{1}^{*}, \Pi_{2}^{F}\left(q_{2}^{*}\right)>\Pi_{1}^{F}\left(q_{1}^{*}\right)$ and $C^{F}\left(q_{1}^{*}\right)<C^{F}\left(q_{2}^{*}\right)$. These results verify that cap-and-trade regulation can lead to higher order quantity from the offshore supplier, higher profit and more carbon emissions than carbon tax regulation. We also solve problem $P_{0}$ using the same parameter values to obtain the optimal order quantity $q_{0}^{*}=934.29$ and optimal profit $\Pi_{0}^{F}\left(q_{0}^{*}\right)=3.8141 \times 10^{4}$. The optimal solutions of $P_{0}, P_{1}$ and $P_{2}$ show that $q_{0}^{*}>q_{2}^{*}>q_{1}^{*}$ and $\Pi_{2}^{F}\left(q_{2}^{*}\right)>\Pi_{0}^{F}\left(q_{0}^{*}\right)>\Pi_{1}^{F}\left(q_{1}^{*}\right)$, consistent with the theoretical results derived in the previous section. Since some carbon emission permits can be sold to generate revenue, the profit of the retailer under cap-and-trade regulation is higher than that without carbon emission consideration. It is opposite in the case under the carbon tax regulation.

We note that the integer mean and variance values are used in above numerical examples for simplicity. Furthermore, the order quantity is not required to be an integer number because the existence and uniqueness of the optimal order quantity are based on the assumption that the solution is a continuous variable similar to that in some of the existing models, e.g. Kevork (2010), Andersson et al. (2013), and Choi (2013).

The effects of demand uncertainty on optimal decision can be observed by comparing the results corresponding to different demand standard deviations. Table 2 shows the results for $P_{1}$ and $P_{2}$ corresponding to different $\sigma$ values given in the first column of the table. From Table 2, we can see that the optimal order quantities and profits for both $P_{1}$ and $P_{2}$ decrease as $\sigma$ increases. An increase of $\sigma$ leads to a higher value of the coefficient of variation $(\mathrm{CV})$, which leads the retailer to become more conservative and to order less products under the worst distribution of demand. In particular, when $\sigma=980$, the retailer orders zero quantity from the offshore supplier under carbon tax regulation and the optimal profit is $1.4715 \times 10^{4}$. The decreased order quantity leads to less profit and lower carbon emissions. Moreover, the results show that the solutions under carbon tax regulation are more sensitive to the change of $\sigma$. For instance, when $\sigma$ changes from 294 to $392, q_{1}^{*}, \Pi_{1}^{F}\left(q_{1}^{*}\right)$ and $C^{F}\left(q_{1}^{*}\right)$ are reduced by $19.6 \%, 5.3 \%$ and $10.3 \%$ respectively while $q_{2}^{*}, \Pi_{2}^{F}\left(q_{2}^{*}\right)$ and $C^{F}\left(q_{2}^{*}\right)$ are reduced by $5.4 \%, 3.8 \%$ and $0.3 \%$, respectively.

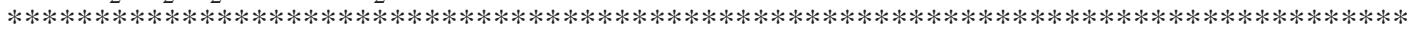

****************************** Please insert Table 2. $* * * * * * * * * * * * * * * * * * * * * * * * * * * * *$

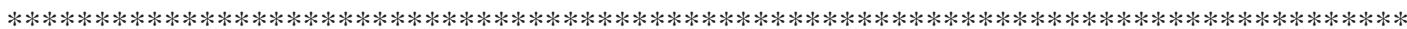

Also through this example, we further investigate the effects of carbon parameters $c_{t}, K, c_{b}$ and $c_{s}$ on order quantities, profits and corresponding carbon emission levels under carbon tax and cap-and-trade regulations. The results are 
summarized in Figures 2 to 5.

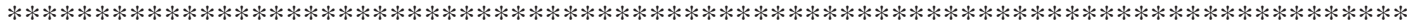

**************************** Please insert Figures 2-5 $* * * * * * * * * * * * * * * * * * * * * * * * * * * * *$

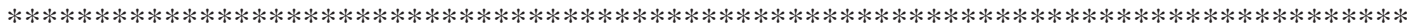

Figure 2 shows the effects of carbon tax $c_{t}$ on optimal order quantity, optimal profit and corresponding carbon emission level. We have the following observations for carbon tax regulation.

1) As $c_{t}$ increases, the optimal order quantity, the optimal profit and the corresponding carbon emission level decrease. Moreover, the profit is indeed a decreasing and convex function of $c_{t}$ while the order quantity and the carbon emission level are decreasing and concave with respect to $c_{t}$. Increasing the value of $c_{t}$ urges the retailer to reduce the order quantity from the offshore supplier to curb the carbon emissions. A decrease of the order quantity from the offshore supplier also leads to a decrease of the ordering cost from the offshore supplier. Meanwhile, the retailer has to order more quantity from the onshore supplier to meet the market demand and this leads to an increase of the ordering cost from the onshore supplier. Under this scenario, although the total carbon tax cost decreases as $c_{t}$ increases, it may not be sufficient to increase the retailer's profit. For example, when $c_{t}$ changes from 3.2 to 3.6, the order quantity from the offshore supplier and the carbon emission level decrease respectively from 602.67 to 531.70 and from 3372.3 to 3054.7. Furthermore, the ordering cost from the offshore supplier and the carbon emission level decrease respectively by 227.10 and 935.34 while the ordering cost from the onshore supplier increase by 1751.52 . The profit of the retailer then decreases as $c_{t}$ increases. In addition, from the retailer perspective, although the carbon emission level can be reduced by increasing the value of $c_{t}$, the retailer has to pay for the decease in profit. This also leads the retailer to either invest the technology or transfer to the place with free policy. On the other hand, the government should strengthen its supervision to guarantee the effectiveness of carbon tax regulation.

2) As $c_{t}$ increases, the optimal order quantity and the optimal profit are strictly less than those corresponding values without carbon emission consideration, i.e., $q_{1}^{*}<q_{0}^{*}$ and $\Pi_{1}^{F}\left(q_{1}^{*}\right)<\Pi_{0}^{F}\left(q_{0}^{*}\right)$. In particular, when $c_{t}=4.4$, the retailer will not order any product from the offshore supplier in order to avoid possible high carbon tax. Under this scenario, the market demand is fully satisfied by the on-shore supplier with minimum carbon emissions. This implies that increasing value of $c_{t}$ leads the retailer to adopt more robust policy with reducing order quantity from offshore for less carbon emissions.

3) As $c_{t}$ increases, the differences in the order quantity and the profit between the model under carbon tax regulation and that without carbon emission consideration become more apparent. For example, when the value of $c_{t}$ is changed from 3.2 to 4.0 , the difference in the order quantity between the model under carbon tax regulation and that without carbon emission consideration is increased by $60.73 \%$, and the difference in the profit is increased by $18.00 \%$. This also implies that the retailer prefers to accept lower carbon tax to achieve a low carbon economy when carbon tax regulation is imposed on the retailer.

Figure 3 shows the effects of carbon cap $K$ on optimal order quantity, optimal profit and corresponding carbon emission. We have the following observations for cap-and-trade regulation.

1) As $K$ increases, the optimal order quantity and the corresponding carbon emission level first remain unchanged, then increase and then keep unchanged. Figures 3(a) and 3(c) show that the optimal order quantity and the corresponding carbon emission level are not affected by the change of $K$ when $K \leq 3000$ or $K \geq 4000$. On the other hand, the carbon emission level is higher than $K$ when $K<3000$ and the carbon emission level is less than $K$ when $K \geq 4000$. Figures 3(a) and 3(c) also show that the optimal order quantity and the corresponding carbon emission level both increase with the increase of the carbon cap when $3000<K<4000$. Under this scenario, the carbon emission level of the retailer is close or equal to $K$. This implies that if the difference between the carbon emission level and carbon cap is relatively large, the retailer adopts a robust strategy and keeps the order quantity from the offshore supplier unchanged to attain more profit or less cost when $K$ increases. When the $K$ value is outside this range, the retailer will order more quantity from offshore supplier to reduce the gap between its carbon emission level and the carbon cap when $K$ increases.

2) As $K$ increases, the optimal profit approximately linearly increases. This indicates that the profit of the retailer is sensitive to the changes of the carbon cap and the retailer either needs to buy less carbon emission permits or needs to sell more permits when the value of the carbon cap changes. Figures 3(b) and 3(c) also indicate that increasing the emission cap leads initially to a larger relative profit increase than the relative emission increase. For example, when the value of $K$ is changed from 4000 to 6000 , the profit of the retailer increases by $10.76 \%$ while the carbo emission level remains unchanged. When $K$ is close to 4500 , the profit becomes higher than that without carbon emission 
consideration. This implies that when the carbon cap is relatively large, the retailer can sell the more carbon emission permits to obtain more revenue. This observation reveals one of the main reasons that cap-and-trade regulation is preferable to carbon tax regulation.

From Figures 4 and 5, we further have the following observations for cap-and-trade regulation. We let $K$ be 3000 and 4000 and present corresponding results in Figures 4 and 5, respectively, to investigate the effects of $c_{b}$ and $c_{s}$ more closely.

1) As $c_{b}$ increases, the optimal order quantity, the optimal profit and the carbon emission level first decrease and then keep unchanged at the level corresponding to the carbon cap $K$. For our numerical example, when $K=3000$, the carbon emission level is higher than or equal to the value of carbon cap. Increasing the value of $c_{b}$ urges the retailer to order less quantity from the offshore supplier such as to reduce carbon emissions. The reduced order quantity from the offshore supplier leads to a decrease of the ordering cost, and a reduction of the carbon emission leads to a decrease of the cost of buying carbon emission permits. Although the ordering cost from the offshore supplier and the cost of buying carbon emission permits decrease, it may not be sufficient to increase the retailer's profit because the order quantity and the corresponding cost from the onshore supplier increase. For example, when $c_{b}$ changes from 2.8 to 3.2 , the order quantity from the offshore supplier and the carbon emission level decrease respectively from 652.10 to 602.67 and from 3603.7 to 3372.3. The ordering cost from the offshore supplier and the cost of buying carbon emission permits decrease by 494.34 and 499 respectively, while the ordering cost from the onshore supplier increases by 1148.32. Hence, the profit will decrease as $c_{b}$ increases. On the other hand, when the value of $c_{b}$ is higher than or equal to 4.0 in this example, the retailer orders the same quantity from the offshore supplier to keep the carbon emission at the level of the carbon cap. Under this scenario, the retailer does not need to buy carbon emission permits and the profit remains unchanged when $c_{b}$ increases from 4.0.

2) As $c_{s}$ increases, the optimal order quantity, the optimal profit and the carbon emission level first keep unchanged at the level corresponding to the carbon cap $K$, and then the order quantity and the carbon emission decrease while the profit increases. For our numerical example with $K=4000$, the carbon emission level is lower than or equal to the value of carbon cap. When the value of $c_{s}$ changes to 1.6 or less, the retailer will not sell carbon emission permits. The order quantity from the offshore supplier is kept the same and the carbon emission level equals to the carbon cap. Increasing the value of $c_{s}$ from 1.6 urges the retailer to reduce the order quantity from the offshore supplier to curb the carbon emissions. Under this scenario, the ordering cost from the offshore supplier decreases and the retailer can sell extra carbon emission permits to generate more revenue. On the other hand, the ordering cost from onshore supplier increases because the retailer should order more quantity from onshore supplier to meet the market demand. For example, when $c_{s}$ changes from 2.4 to 2.8, the order quantity from the offshore supplier and the carbon emission level decrease respectively from 691.40 to 652.10 and from 3796.5 to 3603.7. Also the ordering cost from the offshore supplier decreases by 392.97 while the revenue of selling carbon emission permits and the ordering cost from the onshore supplier increase by 621.24 and 850.65 , respectively. The sum of a decrease of the ordering cost from the offshore supplier and the increase of the revenue of selling extra carbon emission permits are higher than the increase of the ordering cost from the onshore supplier, which leads to a higher profit.

3) When $c_{b}$ changes from 2.0 to 4.4 , the order quantity from the offshore supplier and the retailer's profit are at least $22.3 \%$ and $7.8 \%$, respectively, less than those without carbon consideration. The lower value of $c_{b}$ makes the retailer's profit closer to that without carbon consideration. When $c_{s}$ changes from 0.8 to 3.2 , the order quantity from the offshore supplier and the retailer's profit are at least $21.8 \%$ and $1.6 \%$, respectively, less than those without carbon considerations. The higher value of $c_{s}$ makes the retailer's profit closer to that without consideration. Combining Theorem 4.7 and Corollary 4.14, we have that the retailer's profit under carbon cap-and-trade regulation may be higher than that under carbon tax regulation. This implies that comparing with the effects of decreasing $c_{b}$, increasing $c_{s}$ is more likely to make the retailer's profit be higher than that without carbon consideration.

\section{Conclusion}

Making right decisions in supplier selection plays an important role in enhancing service and in coping with ever changing market demand. In addition, carbon emission control and reduction have received considerable attentions from researchers due to global climate change concerns. Carbon tax and carbon cap-and-trade as two effective regulations are implemented in many countries and economic regions for carbon emission reduction. Motivated by the 
challenges arising from these practices, we construct two distributionally robust newsvendor models with dual sourcing under these two carbon regulations. We follow the max-min approach to derive optimal order quantity for each model. When the mean and variance of the demand distribution are known, we solve these problems analytically under different carbon regulation conditions. We also use several numerical examples to illustrate the models and their analytical results. Our theoretical and numerical analyses show that (i) Under carbon tax regulation, zero order quantity from the offshore supplier can reduce the negative effects of demand uncertainty and also may lead to a positive profit. (ii) The profit of the retailer under carbon tax regulation is less than that without carbon emissions. (iii) When the emission permits buying and selling prices are different, the carbon cap plays an important role in generating profits for the retailer.

The proposed model can be extended in several ways. For instance, we use a maximin approach to derive robust solutions for the models developed in this paper. As pointed out in Yue et al. (2006) and Andersson et al. (2013), other methods such as minimax regret and maximum entropy can lead to less conservative solutions in solving newsvendor problems without carbon emissions consideration when partial demand information is known. Thus, it should be interesting to see if the maximin expected profit approach can do better than other methods when different carbon regulations are in place. On the other hand, the selling price and the investment for emission reduction may influence the market demand when carbon emission is considered. These issues can also be investigated in our future research by incorporating them into the distributionally robust newsvendor problems.

\section{Acknowledgement}

The authors would like to thank the Editor-in-Chief, Professor Mohamed I Dessouky and the anonymous referees for their valuable comments and suggestions which have significantly improved the quality of the paper.

\section{Appendix}

\section{Appendix A. Proof of Lemma 4.2}

From Eq.(9), taking the first partial derivative of $C^{F}(q)$ with respect to $q$, we have

$$
\begin{aligned}
\frac{\partial C^{F}(q)}{\partial q} & =e_{1}+e_{2}+\frac{1}{2}\left(e_{2}+e_{3}\right)\left\{\left[\sigma^{2}+(q-\mu)^{2}\right]^{-\frac{1}{2}}(q-\mu)-1\right\} \\
& =\frac{1}{2}\left[\sigma^{2}+(q-\mu)^{2}\right]^{-\frac{1}{2}}\left\{\left(2 e_{1}+e_{2}-e_{3}\right)\left[\sigma^{2}+(q-\mu)^{2}\right]^{\frac{1}{2}}+\left(e_{2}+e_{3}\right)(q-\mu)\right\}
\end{aligned}
$$

It is easily observed that $\frac{\partial C^{F}(q)}{\partial q}>0$ when $q \geq \mu$. On the other hand, when $q<\mu$, we have $\left(2 e_{1}+e_{2}-e_{3}\right)\left[\sigma^{2}+(q-\right.$ $\left.\mu)^{2}\right]^{\frac{1}{2}}>\left(2 e_{1}+e_{2}-e_{3}\right)(\mu-q)$. Using $e_{1}>e_{3}$, we further have $\left(2 e_{1}+e_{2}-e_{3}\right)\left[\sigma^{2}+(q-\mu)^{2}\right]^{\frac{1}{2}}+\left(e_{2}+e_{3}\right)(q-\mu)>$ $2\left(e_{1}-e_{3}\right)(\mu-q)>0$. So we have $\frac{\partial C^{F}(q)}{\partial q}>0$ which implies that $C^{F}(q)$ is an increasing function of $q$. With $C^{F}(0)=\frac{1}{2}\left(e_{2}+e_{3}\right)\left(\sigma^{2}+\mu^{2}\right)^{\frac{1}{2}}-\frac{1}{2}\left(e_{2}-e_{3}\right) \mu>0$ and $q \geq 0$, we have $C^{F}(q) \geq C^{F}(0)>0$. We take the second partial derivative of $C^{F}(q)$ with respect to $q$ and have $\frac{\partial^{2} C^{F}(q)}{\partial q^{2}}=\frac{1}{2}\left(e_{2}+e_{3}\right) \sigma^{2}\left[\sigma^{2}+(q-\mu)^{2}\right]^{-\frac{3}{2}}>0$. This implies that $C^{F}(q)$ is a positive increasing convex function of $q$.

\section{Appendix B. Proof of Theorem 4.3}

Taking the first and second partial derivative of $\Pi_{1}^{F}(q)$ in Eq.(10) with respect to $q$, we have

$$
\begin{aligned}
\frac{\partial \Pi_{1}^{F}(q)}{\partial q} & =v-c-c_{t}\left(e_{1}+e_{2}\right)-\frac{1}{2}\left[c+a-v+c_{t}\left(e_{2}+e_{3}\right)\right]\left\{\left[\sigma^{2}+(q-\mu)^{2}\right]^{-\frac{1}{2}}(q-\mu)-1\right\} \\
\frac{\partial^{2} \Pi_{1}^{F}(q)}{\partial q^{2}} & =-\frac{1}{2}\left[c+a-v+c_{t}\left(e_{2}+e_{3}\right)\right] \sigma^{2}\left[\sigma^{2}+(q-\mu)^{2}\right]^{-\frac{3}{2}} .
\end{aligned}
$$


From Eq.(B.2), we easily have $\frac{\partial^{2} \Pi_{1}^{F}(q)}{\partial q^{2}}<0$ which implies that $\Pi_{1}^{F}(q)$ is a concave function of $q$.

Solving $\frac{\partial \Pi_{1}^{F}(q)}{\partial q}=0$, we have

$$
\frac{q-\mu}{\left[\sigma^{2}+(q-\mu)^{2}\right]^{\frac{1}{2}}}=\frac{v-c+a+c_{t}\left(e_{3}-2 e_{1}-e_{2}\right)}{c+a-v+c_{t}\left(e_{2}+e_{3}\right)} .
$$

From Eq. (B.3), we have the necessary and sufficient condition for comparing $q$ and $\mu$. Specifically, $q \geq \mu$ if and only if $\sigma+c_{t}\left(e_{3}-e_{1}\right) \geq c-v+c_{t}\left(e_{1}+e_{2}\right)$ holds, and $q<\mu$ if and only if $\sigma+c_{t}\left(e_{3}-e_{1}\right)<c-v+c_{t}\left(e_{1}+e_{2}\right)$ holds. Simplifying Eq. (B.3), we have

$$
\begin{aligned}
q_{t} & =\mu+\frac{\sigma}{2}\left[\left(\frac{a-c_{t} e_{1}+c_{t} e_{3}}{c-v+c_{t} e_{1}+c_{t} e_{2}}\right)^{\frac{1}{2}}-\left(\frac{c-v+c_{t} e_{1}+c_{t} e_{2}}{a-c_{t} e_{1}+c_{t} e_{3}}\right)^{\frac{1}{2}}\right] \\
& =\mu+\frac{\sigma}{2}\left(\sqrt{\frac{A_{1}}{B_{1}}}-\sqrt{\frac{B_{1}}{A_{1}}}\right) .
\end{aligned}
$$

Obviously, if $q_{t}>0$, i.e., $\frac{\mu}{\sigma}>\frac{B_{1}-A_{1}}{2 \sqrt{A_{1} B_{1}}}$, we obtain that the optimal robust order quantity of $P_{1}$ is $q_{t}$, i.e., $q_{1}^{*}=q_{t}$. Otherwise, $q_{1}^{*}=0$ because of the concavity of $\Pi_{1}^{F}(q)$. Consequently, we have $q_{1}^{*}=\max \left\{q_{t}, 0\right\}$.

\section{Appendix C. Proof of Corollary 4.4}

Firstly, we formulate the following function $f(x)=x-\frac{1}{x}$. From $f^{\prime}(x)=1+\frac{1}{x^{2}}>0$, we have that $f(x)$ is an increasing function of $x$. Moreover, when $\frac{\sigma}{\mu}>\frac{2 \sqrt{A_{1} B_{1}}}{B_{1}-A_{1}}$ and $B_{1}>A_{1}$, from Eq. (11), we easily have $q_{t}=\mu+\frac{\sigma}{2}\left(\sqrt{\frac{A_{1}}{B_{1}}}-\right.$ $\left.\sqrt{\frac{B_{1}}{A_{1}}}\right)=\mu\left[1-\frac{\sigma\left(B_{1}-A_{1}\right)}{2 \mu \sqrt{A_{1} B_{1}}}\right]<0$. From Theorem 4.3, we have $q_{1}^{*}=\max \left\{q_{t}, 0\right\}=0$. Substituting $q_{1}^{*}=0$ into Eq. (10), we have

$$
\Pi_{1}^{F}\left(q_{1}^{*}\right)=\Pi_{1}^{F}(0)=\frac{1}{2}\left[2 p-c-v-a+c_{t}\left(e_{2}-e_{3}\right)\right] \mu-\frac{1}{2}\left[c+a-v+c_{t}\left(e_{2}+e_{3}\right]\left(\sigma^{2}+\mu^{2}\right)^{\frac{1}{2}} .\right.
$$

Using Eq.(C.1), we prove that Corollary 4.4 (i) and (ii) hold.

(i) When $A_{1} B_{2}<A_{2} B_{1}$, we have $\sqrt{\frac{B_{1}}{A_{1}}}-\sqrt{\frac{A_{1}}{B_{1}}}>\sqrt{\frac{B_{2}}{A_{2}}}-\sqrt{\frac{A_{2}}{B_{2}}}$ by using the property of $f(x)$. We further have $\frac{\sqrt{A_{2} B_{2}}}{B_{2}-A_{2}}>\frac{\sqrt{A_{1} B_{1}}}{B_{1}-A_{1}}$. Hence, when $\frac{\sigma}{\mu}<\frac{2 \sqrt{A_{2} B_{2}}}{B_{2}-A_{2}}$, we have

$$
\left(\sigma^{2}+\mu^{2}\right)^{\frac{1}{2}}<\frac{\mu\left(B_{2}+A_{2}\right)}{B_{2}-A_{2}}=\frac{\mu\left[2 p-v-c-a+c_{t}\left(e_{2}-e_{3}\right)\right]}{c+a-v+c_{t}\left(e_{2}+e_{3}\right)} .
$$

From Eqs. (C.1) and (C.2), we have $\Pi_{1}^{F}\left(q_{1}^{*}\right)=\Pi_{1}^{F}(0)>0$.

(ii) When $A_{1} B_{2}<A_{2} B_{1}$ and $\frac{\sigma}{\mu} \geq \frac{2 \sqrt{A_{2} B_{2}}}{B_{2}-A_{2}}$, we also have

$$
\left(\sigma^{2}+\mu^{2}\right)^{\frac{1}{2}} \geq \frac{\mu\left(B_{2}+A_{2}\right)}{B_{2}-A_{2}}=\frac{\mu\left[2 p-v-c-a+c_{t}\left(e_{2}-e_{3}\right)\right]}{c+a-v+c_{t}\left(e_{2}+e_{3}\right)} .
$$

From Eqs. (C.1) and (C.3), we have $\Pi_{1}^{F}\left(q_{1}^{*}\right)=\Pi_{1}^{F}(0) \leq 0$.

On the other hand, when $A_{1} B_{2} \geq A_{2} B_{1}$, we have $\frac{\sqrt{A_{2} B_{2}}}{B_{2}-A_{2}} \leq \frac{\sqrt{A_{1} B_{1}}}{B_{1}-A_{1}}$ because $f(x)$ is an increasing function of $x$. Recalling that $\frac{\sigma}{\mu}>\frac{2 \sqrt{A_{1} B_{1}}}{B_{1}-A_{1}}$, we have $\frac{\sigma}{\mu}>\frac{2 \sqrt{A_{2} B_{2}}}{B_{2}-A_{2}}$. Under this scenario, we have that Eq. (C.3) also holds. Hence, from Eq.(C.1), we have $\Pi_{1}^{F}\left(q_{1}^{*}\right)=\Pi_{1}^{F}(0) \leq 0$.

Secondly, when $q_{t}>0$, from Eq. (B.4), we have

$$
\begin{aligned}
q_{t}-\mu & =\frac{\sigma}{2}\left[\left(\frac{a-c_{t} e_{1}+c_{t} e_{3}}{c-v+c_{t} e_{1}+c_{t} e_{2}}\right)^{\frac{1}{2}}-\left(\frac{c-v+c_{t} e_{1}+c_{t} e_{2}}{a-c_{t} e_{1}+c_{t} e_{3}}\right)^{\frac{1}{2}}\right] \\
& =\frac{\sigma\left[a-c+v+c_{t}\left(e_{3}-2 e_{1}-e_{2}\right)\right]}{2\left[c-v+c_{t}\left(e_{1}+e_{2}\right)\right]^{\frac{1}{2}}\left[a-c_{t}\left(e_{1}-e_{3}\right)\right]^{\frac{1}{2}}}
\end{aligned}
$$


and

$$
\begin{aligned}
{\left[\sigma^{2}+\left(q_{t}-\mu\right)^{2}\right]^{\frac{1}{2}}-\left(q_{t}-\mu\right) } & =\frac{2\left[c-v+c_{t}\left(e_{1}+e_{2}\right)\right]\left(q_{t}-\mu\right)}{v-c+a+c_{t}\left(e_{3}-2 e_{1}-e_{2}\right)} \\
& =\sigma\left[\frac{c-v+c_{t}\left(e_{1}+e_{2}\right)}{a-c_{t}\left(e_{1}-e_{3}\right)}\right]^{\frac{1}{2}}
\end{aligned}
$$

Substituting Eqs.(C.4) and (C.5) into Eq.(10), we have

$$
\begin{aligned}
\Pi_{1}^{F}\left(q_{1}^{*}\right) & =\Pi_{1}^{F}\left(q_{t}\right)=\left(p-c-c_{t} e_{1}\right) \mu-\sigma\left[a-c_{t}\left(e_{1}-e_{3}\right)\right]^{\frac{1}{2}}\left[c-v+c_{t}\left(e_{1}+e_{2}\right)\right]^{\frac{1}{2}} \\
& =\left(p-c-c_{t} e_{1}\right) \mu-\sigma \sqrt{A_{1} B_{1}} .
\end{aligned}
$$

On the other hand, using Eq. (C.6), we prove that Corollary 4.4 (iii) holds.

(iii) When $\frac{\sigma}{\mu} \leq \frac{2 \sqrt{A_{1} B_{1}}}{B_{1}-A_{1}}$ and $B_{1}>A_{1}$, we have $q_{t}=\mu+\frac{\sigma}{2}\left(\sqrt{\frac{A_{1}}{B_{1}}}-\sqrt{\frac{B_{1}}{A_{1}}}\right)>0$. From Theorem 4.3, we have $q_{1}^{*}=\max \left\{q_{t}, 0\right\}=q_{t}$. Hence, when $p>c+c_{t} e_{1}+\frac{2 A_{1} B_{1}}{B_{1}-A_{1}}$, from Eq. (C.6), we have

$$
\begin{aligned}
\Pi_{1}^{F}\left(q_{1}^{*}\right) & =\left(p-c-c_{t} e_{1}\right) \mu-\sigma \sqrt{A_{1} B_{1}} \\
& \geq \mu\left(p-c-c_{t} e_{1}-\frac{a A_{1} B_{1}}{B_{1}-A_{1}}\right)>0 .
\end{aligned}
$$

\section{Appendix D. Proof of Theorem 4.6}

From Theorem 4.3, we have that $q_{1}^{*}=q_{t}$ when $q_{t}>0$, otherwise $q_{1}^{*}=0$. When $q_{t}>0$, from Eq.(C.6), we take the first and second partial derivatives of $\Pi_{1}^{F}\left(q_{1}^{*}\right)$ with respect to $c_{t}$ and have

$$
\begin{aligned}
\frac{\partial \Pi_{1}^{F}\left(q_{1}^{*}\right)}{\partial c_{t}} & =-e_{1} \mu-\frac{\sigma}{2}\left\{\left(e_{1}+e_{2}\right)\left[\frac{a-c_{t}\left(e_{1}-e_{3}\right)}{c-v+c_{t}\left(e_{1}+e_{2}\right)}\right]^{\frac{1}{2}}-\left(e_{1}-e_{3}\right)\left[\frac{c-v+c_{t}\left(e_{1}+e_{2}\right)}{a-c_{t}\left(e_{1}-e_{3}\right)}\right]^{\frac{1}{2}}\right\} \\
& =-e_{1} q_{t}-\frac{\sigma}{2}\left[e_{2} \sqrt{\frac{A_{1}}{B_{1}}}+e_{3} \sqrt{\frac{B_{1}}{A_{1}}}\right]<0
\end{aligned}
$$

and

$$
\begin{aligned}
\frac{\partial^{2} \Pi_{1}^{F}\left(q_{1}^{*}\right)}{\partial c_{t}^{2}} & =\frac{\sigma}{4}\left[a-c_{t}\left(e_{1}-e_{3}\right)\right]^{-\frac{3}{2}}\left[c-v+c_{t}\left(e_{1}+e_{2}\right)\right]^{-\frac{3}{2}}\left[a\left(e_{1}+e_{2}\right)+(c-v)\left(e_{1}-e_{3}\right)\right]^{2} \\
& =\frac{\sigma}{4}\left[a\left(e_{1}+e_{2}\right)+(c-v)\left(e_{1}-e_{3}\right)\right]^{2}\left(A_{1} B_{1}\right)^{-\frac{3}{2}}>0 .
\end{aligned}
$$

When $q_{t}=0$, we take the first partial derivatives of $\Pi_{1}^{F}\left(q_{1}^{*}\right)$ in Eq.(C.1) with respect to $c_{t}$ and have

$$
\frac{\partial \Pi_{1}^{F}\left(q_{1}^{*}\right)}{\partial c_{t}}=\frac{1}{2}\left(e_{2}-e_{3}\right) \mu-\frac{1}{2}\left(e_{2}+e_{3}\right)\left(\sigma^{2}+\mu^{2}\right)^{\frac{1}{2}}<0,
$$

which implies that $\Pi_{1}^{F}\left(q_{1}^{*}\right)$ is a strictly decreasing function of $c_{t}$ when $q_{t}<0$. Combining Eq.(D.2), we have that $\Pi_{1}^{F}\left(q_{1}^{*}\right)$ is a decreasing and convex function of $c_{t}$.

Similarly, when $q_{t}>0$, we substitute Eq.(11) into Eq.(9) and have

$$
\begin{aligned}
C^{F}\left(q_{1}^{*}\right) & =C^{F}\left(q_{t}\right)=e_{1} \mu+\frac{\sigma}{2}\left(e_{1}+e_{2}\right) \sqrt{\frac{A_{1}}{B_{1}}}-\frac{\sigma}{2}\left(e_{1}-e_{3}\right) \sqrt{\frac{B_{1}}{A_{1}}} \\
& =e_{1} \mu+\frac{\sigma}{2}\left(e_{1}+e_{2}\right)\left[\frac{a-c_{t}\left(e_{1}-e_{3}\right)}{c-v+c_{t}\left(e_{1}+e_{2}\right)}\right]^{\frac{1}{2}}-\frac{\sigma}{2}\left(e_{1}-e_{3}\right)\left[\frac{c-v+c_{t}\left(e_{1}+e_{2}\right)}{a-c_{t}\left(e_{1}-e_{3}\right)}\right]^{\frac{1}{2}} .
\end{aligned}
$$


Taking the first partial derivatives of $C^{F}\left(q_{1}^{*}\right)$ in Eq.(D.4) with respect to $c_{t}$, we have

$$
\begin{aligned}
\frac{\partial C^{F}\left(q_{1}^{*}\right)}{\partial c_{t}} & =-\frac{\sigma}{4}\left[a-c_{t}\left(e_{1}-e_{3}\right)\right]^{-\frac{3}{2}}\left[c-v+c_{t}\left(e_{1}+e_{2}\right)\right]^{-\frac{3}{2}}\left[a \left(e_{1}+e_{2}+(c-v)\left(e_{1}-e_{3}\right]^{2}\right.\right. \\
& =-\frac{\sigma}{4}\left[a \left(e_{1}+e_{2}+(c-v)\left(e_{1}-e_{3}\right]^{2}\left(A_{1} B_{1}\right)^{-\frac{3}{2}}<0,\right.\right.
\end{aligned}
$$

which implies that $C^{F}\left(q_{1}^{*}\right)$ is a strictly decreasing function of $c_{t}$. When $q_{t}<0$, from Eq.(9), we easily have that $C^{F}\left(q_{1}^{*}\right)$ is not effected by $c_{t}$. Hence, we can obtain that $C^{F}\left(q_{1}^{*}\right)$ is a non-increasing function of $c_{t}$.

\section{Appendix E. Proof of Theorem 4.7}

From Theorem 4.3, we have $q_{1}^{*}=q_{t}$ when $q_{t}>0$. Using the fact that $a-c_{t}\left(e_{1}-e_{3}\right)<a$ and $c-v+c_{t}\left(e_{1}+e_{2}\right)>c-v$, we have $q_{t}<q_{0}^{*}$ by comparing Eqs. (7) with (11). When $q_{t}<0$, we easily have $q_{1}^{*}=0<q_{0}^{*}$. Hence, we have $q_{1}^{*}<q_{0}^{*}$.

On the other hand, from Eqs.(5) and (6), we have that $\Pi_{1}(q)=\Pi_{0}(q)-c_{t} C(q)$ holds for any $q \geq 0$. Using Lemma 4.1, we further have that $\Pi_{1}^{F}(q)=\Pi_{0}^{F}(q)-c_{t} C^{F}(q)$ hold for any given demand distribution $F$. Then we have $\Pi_{1}^{F}\left(q_{1}^{*}\right)=\Pi_{0}^{F}\left(q_{1}^{*}\right)-c_{t} C^{F}\left(q_{1}^{*}\right)<\Pi_{0}^{F}\left(q_{1}^{*}\right)$ because of $C^{F}\left(q_{1}^{*}\right)>0$. Using the optimality of $q_{0}^{*}$ for problem $P_{0}$, we have $\Pi_{0}^{F}\left(q_{1}^{*}\right) \leq \Pi_{0}^{F}\left(q_{0}^{*}\right)$. Hence we have $\Pi_{1}^{F}\left(q_{1}^{*}\right)<\Pi_{0}^{F}\left(q_{0}^{*}\right)$.

\section{Appendix F. Proof of Lemma 4.8}

Substituting Eq.(9) into $C^{F}(q)=K$, we have

$$
\left(e_{1}+e_{2}\right) q-e_{2} \mu+\frac{1}{2}\left(e_{2}+e_{3}\right)\left\{\left[\sigma^{2}+(q-\mu)^{2}\right]^{\frac{1}{2}}-(q-\mu)\right\}=K .
$$

Setting $K_{1}=2 K+\left(e_{2}-e_{3}\right) \mu$ and simplifying Eq.(F.1), we have

$$
\left(e_{2}+e_{3}\right)\left[\sigma^{2}+(q-\mu)^{2}\right]^{\frac{1}{2}}=K_{1}-\left(2 e_{1}+e_{2}-e_{3}\right) q .
$$

From Eq.(F.2), we can obtain

$$
q<\frac{K_{1}}{2 e_{1}+e_{2}-e_{3}}
$$

Rearranging Eq.(F.2), we have

$$
4\left(e_{1}+e_{2}\right)\left(e_{1}-e_{3}\right) q^{2}+2 q\left[\left(e_{2}+e_{3}\right)^{2} \mu-\left(2 e_{1}+e_{2}-e_{3}\right) K_{1}\right]+K_{1}^{2}-\left(e_{2}+e_{3}\right)^{2}\left(\mu^{2}+\sigma^{2}\right)=0 .
$$

Let $\Delta=\left[K_{1}-\mu\left(2 e_{1}+e_{2}-e_{3}\right)\right]^{2}+4\left(e_{1}+e_{2}\right)\left(e_{1}-e_{3}\right) \sigma^{2}$. Solving Eq.(F.4), we have two roots as

$$
q_{c 1}=\frac{K_{1}\left(2 e_{1}+e_{2}-e_{3}\right)-\mu\left(e_{2}+e_{3}\right)^{2}-\left(e_{2}+e_{3}\right) \sqrt{\Delta}}{4\left(e_{1}+e_{2}\right)\left(e_{1}-e_{3}\right)}
$$

and

$$
q_{c 2}=\frac{K_{1}\left(2 e_{1}+e_{2}-e_{3}\right)-\mu\left(e_{2}+e_{3}\right)^{2}+\left(e_{2}+e_{3}\right) \sqrt{\Delta}}{4\left(e_{1}+e_{2}\right)\left(e_{1}-e_{3}\right)} .
$$

Next, we will verify that whether $q_{c 1}$ and $q_{c 2}$ satisfy Eq.(F.3). For $q_{c 2}$ determined by Eq.(F.6), we easily prove that when $K_{1} \geq \mu\left(2 e_{1}+e_{2}-e_{3}\right)$, the following inequality holds

$$
\left(2 e_{1}+e_{2}-e_{3}\right) \sqrt{\Delta}>\left(e_{2}+e_{3}\right)\left[\mu\left(2 e_{1}+e_{2}-e_{3}\right)-K_{1}\right]
$$


On the other hand, when $K_{1}<\mu\left(2 e_{1}+e_{2}-e_{3}\right)$, using the fact that $\left[\mu\left(2 e_{1}+e_{2}-e_{3}\right)-K_{1}\right]^{2}+\left(2 e_{1}+e_{2}-e_{3}\right)^{2} \sigma^{2}>0$, we have

$$
4\left(e_{1}+e_{2}\right)\left(e_{1}-e_{3}\right)\left[\mu\left(2 e_{1}+e_{2}-e_{3}\right)-K_{1}\right]^{2}+4\left(e_{1}+e_{2}\right)\left(e_{1}-e_{3}\right)\left(2 e_{1}+e_{2}-e_{3}\right)^{2} \sigma^{2}>0 .
$$

Using $\left(2 e_{1}+e_{2}-e_{3}\right)^{2}-\left(e_{2}+e_{3}\right)^{2}=4\left(e_{1}+e_{2}\right)\left(e_{1}-e_{3}\right)$, we can express Eq.(F.8) as

$$
\left(2 e_{1}+e_{2}-e_{3}\right)^{2} \Delta>\left(e_{2}+e_{3}\right)^{2}\left[\mu\left(2 e_{1}+e_{2}-e_{3}\right)-K_{1}\right]^{2} .
$$

It is easily observed that Eq.(F.7) also holds for $K_{1} \geq \mu\left(2 e_{1}+e_{2}-e_{3}\right)$, which Eq.(F.7) always holds for any values of $K_{1}$.

From Eq.(F.7), we have

$$
\left(e_{2}+e_{3}\right)\left(2 e_{1}+e_{2}-e_{3}\right) \sqrt{\Delta}>\left(e_{2}+e_{3}\right)^{2}\left[\mu\left(2 e_{1}+e_{2}-e_{3}\right)-K_{1}\right]
$$

and

$$
K_{1}\left(2 e_{1}+e_{2}-e_{3}\right)^{2}-\mu\left(e_{2}+e_{3}\right)^{2}\left(2 e_{1}+e_{2}-e_{3}\right)+\left(e_{2}+e_{3}\right)\left(2 e_{1}+e_{2}-e_{3}\right) \sqrt{\Delta}>4 K_{1}\left(e_{1}+e_{2}\right)\left(e_{1}-e_{3}\right) .
$$

Eq.(F.11) holds because of $\left(e_{2}+e_{3}\right)^{2}=\left(2 e_{1}+e_{2}-e_{3}\right)^{2}-\left(4\left(e_{1}+e_{2}\right)\left(e_{1}-e_{3}\right)\right.$.

Using Eq.(F.6) and rearranging Eq.(F.10), we have

$$
q_{c 2}>\frac{K_{1}}{2 e_{1}+e_{2}-e_{3}} .
$$

This contradicts with Eq.(F.3), which implies that $q_{c 2}$ does not satisfy Eq.(F.1).

Similarly, for any values of $K_{1}$, we can prove that the following equality holds.

$$
\left(2 e_{1}+e_{2}-e_{3}\right) \sqrt{\Delta}>\left(e_{2}+e_{3}\right)\left[K_{1}-\mu\left(2 e_{1}+e_{2}-e_{3}\right)\right],
$$

which is equivalent to

$$
\left(e_{2}+e_{3}\right)\left(2 e_{1}+e_{2}-e_{3}\right) \sqrt{\Delta}>\left(e_{2}+e_{3}\right)^{2}\left[K_{1}-\mu\left(2 e_{1}+e_{2}-e_{3}\right)\right] .
$$

Using $\left(e_{2}+e_{3}\right)^{2}=\left(2 e_{1}+e_{2}-e_{3}\right)^{2}-4\left(e_{1}+e_{2}\right)\left(e_{1}-e_{3}\right)$, we simplify Eq.(F.14) as

$$
\left(e_{2}+e_{3}\right)\left(2 e_{1}+e_{2}-e_{3}\right) \sqrt{\Delta}>K_{1}\left[\left(2 e_{1}+e_{2}-e_{3}\right)^{2}-4\left(e_{1}+e_{2}\right)\left(e_{1}-e_{3}\right)\right]-\mu\left(e_{2}+e_{3}\right)^{2}\left(2 e_{1}+e_{2}-e_{3}\right) .
$$

From Eq.(F.15), we further have

$$
4 K_{1}\left(e_{1}+e_{2}\right)\left(e_{1}-e_{3}\right)>K_{1}\left(2 e_{1}+e_{2}-e_{3}\right)^{2}-\mu\left(e_{2}+e_{3}\right)^{2}\left(2 e_{1}+e_{2}-e_{3}\right)-\left(e_{2}+e_{3}\right)\left(2 e_{1}+e_{2}-e_{3}\right) \sqrt{\Delta} .
$$

Substituting Eq.(F.5) into Eq.(F.16), we have

$$
q_{c 1}<\frac{K_{1}}{2 e_{1}+e_{2}-e_{3}}
$$

which implies that $q_{c 1}$ is a root of Eq.(F.1).

When $K \geq \frac{\left(e_{3}-e_{2}\right) \mu+\left(e_{2}+e_{3}\right) \sqrt{\mu^{2}+\sigma^{2}}}{2}$, we easily have

$$
K_{1} \geq\left(e_{2}+e_{3}\right) \sqrt{\mu^{2}+\sigma^{2}},
$$

and

$$
K_{1}^{2}-\mu^{2}\left(e_{2}+e_{3}\right)^{2} \geq\left(e_{2}+e_{3}\right)^{2} \sigma^{2} .
$$


With $e_{1}>e_{3}$, we can write Eq.(F.19) as

$$
4\left(e_{1}+e_{2}\right)\left(e_{1}-e_{3}\right)\left[K_{1}-\mu\left(e_{2}+e_{3}\right)\right]\left[K_{1}+\mu\left(e_{2}+e_{3}\right)\right] \geq 4\left(e_{1}+e_{2}\right)\left(e_{1}-e_{3}\right)\left(e_{2}+e_{3}\right)^{2} \sigma^{2} .
$$

Using $2\left(e_{1}+e_{2}\right)=\left(2 e_{1}+e_{2}-e_{3}\right)+\left(e_{2}+e_{3}\right)$ and $2\left(e_{1}-e_{3}\right)=\left(2 e_{1}+e_{2}-e_{3}\right)-\left(e_{2}+e_{3}\right)$, we express Eq.(F.20) as

$$
\begin{aligned}
{\left[K_{1}\left(2 e_{1}+e_{2}-e_{3}\right)-\mu\left(e_{2}+e_{3}\right)^{2}\right]^{2} } & -\left[K_{1}\left(e_{2}+e_{3}\right)-\mu\left(e_{2}+e_{3}\right)\left(2 e_{1}+e_{2}-e_{3}\right)\right]^{2} \\
& \geq 4\left(e_{1}+e_{2}\right)\left(e_{1}-e_{3}\right)\left(e_{2}+e_{3}\right)^{2} \sigma^{2},
\end{aligned}
$$

and

$$
K_{1}\left(2 e_{1}+e_{2}-e_{3}\right)-\mu\left(e_{2}+e_{3}\right)^{2} \geq\left(e_{2}+e_{3}\right) \sqrt{\Delta} .
$$

Combining Eqs.(F.5) and (F.22), we easily have $q_{c 1} \geq 0$, which means that Eq.(F.1) has a unique non-negative root. In addition, substituting $K_{1}=2 K+\left(e_{2}-e_{3}\right) \mu$ into the expression of $\Delta$ and Eq.(F.5), and after simplification, we have

$$
\begin{aligned}
\Delta & =\left[K_{1}-\mu\left(2 e_{1}+e_{2}-e_{3}\right)\right]^{2}+4\left(e_{1}+e_{2}\right)\left(e_{1}-e_{3}\right) \sigma^{2} \\
& =4\left[\left(K-e_{1} \mu\right)^{2}+\left(e_{1}+e_{2}\right)\left(e_{1}-e_{3}\right) \sigma^{2}\right]
\end{aligned}
$$

and

$$
q_{c 1}=\frac{2 K\left(2 e_{1}+e_{2}-e_{3}\right)+2 \mu\left(e_{1} e_{2}-e_{1} e_{3}-2 e_{2} e_{3}\right)-\left(e_{2}+e_{3}\right) \sqrt{\Delta}}{4\left(e_{1}+e_{2}\right)\left(e_{1}-e_{3}\right)} .
$$

\section{Appendix G. Proof of Theorem 4.9}

Substituting Eqs.(3) and (4) into Eq.(14), and using Lemma 4.1, we have

$\Pi_{21}^{F}(q)=\left(p-v+c_{s} e_{2}\right) \mu-\frac{1}{2}\left[c+a-v+c_{s}\left(e_{2}+e_{3}\right)\right]\left\{\left[\sigma^{2}+(q-\mu)^{2}\right]^{\frac{1}{2}}-(q-\mu)\right\}-\left[c+c_{s}\left(e_{1}+e_{2}\right)-v\right] q+c_{s} K .(\mathrm{G} .1)$ Taking the first and second second partial derivatives of $\Pi_{21}^{F}(q)$ with respect to $q$, we have

$$
\frac{\partial \Pi_{21}^{F}(q)}{\partial q}=v-c-c_{s}\left(e_{1}+e_{2}\right)-\frac{1}{2}\left[c+a-v+c_{s}\left(e_{2}+e_{3}\right)\right]\left\{\frac{q-\mu}{\left[\sigma^{2}+(q-\mu)^{2}\right]^{\frac{1}{2}}}-1\right\}
$$

and

$$
\frac{\partial^{2} \Pi_{21}^{F}(q)}{\partial q^{2}}=-\frac{\left[c+a-v+c_{s}\left(e_{2}+e_{3}\right)\right] \sigma^{2}}{2\left[\sigma^{2}+(q-\mu)^{2}\right]^{\frac{3}{2}}}<0 .
$$

From $\frac{\partial^{2} \Pi_{21}^{F}(q)}{\partial q^{2}}<0$, we have that $\Pi_{21}^{F}(q)$ is a concave function of $q$. Using $a>c_{s}\left(e_{1}-e_{3}\right)$ and $c>v$, and solving $\frac{\partial \Pi_{21}^{F}(q)}{\partial q}=0$, we have

$$
\begin{aligned}
q_{21} & =\mu+\frac{\sigma}{2}\left\{\left[\frac{a-c_{s}\left(e_{1}-e_{3}\right)}{c-v+c_{s}\left(e_{1}+e_{2}\right)}\right]^{\frac{1}{2}}-\left[\frac{c-v+c_{s}\left(e_{1}+e_{2}\right)}{a-c_{s}\left(e_{1}-e_{3}\right)}\right]^{\frac{1}{2}}\right\} \\
& =\mu+\frac{\sigma}{2}\left(\sqrt{\frac{A_{3}}{B_{3}}}-\sqrt{\frac{B_{3}}{A_{3}}}\right) .
\end{aligned}
$$

Using Lemmas 4.2 and 4.8, we can simplify the constraint $C^{F}(q) \leq K$ in Eq.(15) as

$$
0 \leq q \leq q_{c 1} \text {. }
$$

From Eqs.(G.4) and (G.5), we can obtain the following conclusion. When $\frac{\mu}{\sigma}>\frac{1}{2}\left(\sqrt{\frac{B_{3}}{A_{3}}}-\sqrt{\frac{A_{3}}{B_{3}}}\right)$, i.e., $q_{21}>0$, if $q_{21}>q_{c 1}$, then using the concavity of $\Pi_{21}^{F}(q)$, we have $q_{21}^{*}=q_{c 1}$. Otherwise $q_{21}^{*}=q_{21}$. When $\frac{\mu}{\sigma} \leq \frac{1}{2}\left(\sqrt{\frac{B_{3}}{A_{3}}}-\sqrt{\frac{A_{3}}{B_{3}}}\right)$, i.e., $q_{21} \leq 0$, we have $q_{21}^{*}=0$ with the concavity of $\Pi_{21}^{F}(q)$. Consequently, we have $q_{21}^{*}=\min \left\{\max \left\{q_{21}, 0\right\}, q_{c 1}\right\}$. 


\section{Appendix H. Proof of Corollary 4.10}

(i) When $B_{3} \leq A_{3}$ or $B_{3}>A_{3}$ and $\frac{\sigma}{\mu}<\frac{2 \sqrt{A_{3} B_{3}}}{B_{3}-A_{3}}$, we easily have $q_{21}=\mu+\frac{\sigma}{2}\left(\sqrt{\frac{A_{3}}{B_{3}}}-\sqrt{\frac{B_{3}}{A_{3}}}\right)>0$. From Theorem 4.9, we have $q_{21}^{*}=\min \left\{q_{21}, q_{c 1}\right\}$. If $q_{21}>q_{c 1}$, then $q_{21}^{*}=q_{c 1}$. From Lemma 4.8, we further have $C^{F}\left(q_{c 1}\right)=K$. Moreover, using $a-c_{s}\left(e_{1}-e_{3}\right)<a$ and $c-v+c_{s}\left(e_{1}+e_{2}\right)>c-v$, we have $\frac{A_{3}}{B_{3}}=\frac{a-c_{s}\left(e_{1}-e_{3}\right)}{c-v+c_{s}\left(e_{1}+e_{2}\right)}<\frac{a}{c-v}$ and $\frac{B_{3}}{A_{3}}=\frac{c-v+c_{s}\left(e_{1}+e_{2}\right)}{a-c_{s}\left(e_{1}-e_{3}\right)}>\frac{c-v}{a}$. Comparing Eq. (7) and Eq.(21), we have $q_{21}<q_{0}^{*}$ and $q_{c 1}<q_{0}^{*}$. With Eq.(14), we have $\Pi_{21}^{F}\left(q_{21}^{*}\right)=\Pi_{21}^{F}\left(q_{c 1}\right)=$ $\Pi_{0}^{F}\left(q_{c 1}\right)+c_{s}\left[K-C^{F}\left(q_{c 1}\right)\right]=\Pi_{0}^{F}\left(q_{c 1}\right)<\Pi_{0}^{F}\left(q_{0}^{*}\right)$. The last inequality holds because of the optimal property of $q_{0}^{*}$. Otherwise, i.e., $q_{21} \leq q_{c 1}$, we have $q_{21}^{*}=q_{21}$. When $K>C^{F}\left(q_{0}^{*}\right)$, we have that $q_{0}^{*}$ is one of the feasible solutions of problem $P_{21}$. Hence, we have $\Pi_{21}^{F}\left(q_{21}^{*}\right) \geq \Pi_{0}^{F}\left(q_{0}^{*}\right)$.

(ii) When $B_{3}>A_{3}$ and $\frac{\sigma}{\mu} \geq \frac{2 \sqrt{A_{3} B_{3}}}{B_{3}-A_{3}}$, we easily have $q_{21}<0$ from Eq. (21). Using Theorem 4.9, we further have $q_{21}^{*}=0$. Substituting $q_{21}^{*}=0$ into Eq. (G.1), we have

$$
\left.\Pi_{21}^{F}\left(q_{21}^{*}\right)=\left(p-v+c_{s} e_{2}\right) \mu-\frac{1}{2}\left[c+a-v+c_{s}\left(e_{2}+e_{3}\right)\right]\left\{\left(\sigma^{2}+\mu^{2}\right)^{\frac{1}{2}}+\mu\right)\right\}+c_{s} K .
$$

Hence, when $K>K_{L}$, we have $\Pi_{21}^{F}\left(q_{21}^{*}\right)>0$, where $K_{L}=\frac{1}{2 c_{s}}\left\{\left[c+a-v+c_{s}\left(e_{2}+e_{3}\right)\right]\left(\sigma^{2}+\mu^{2}\right)^{\frac{1}{2}}-[2 p-v-c-a+\right.$ $\left.\left.c_{s}\left(e_{2}-e_{3}\right)\right] \mu\right\}$.

\section{Appendix I. Proof of Theorem 4.13}

We first will prove $q_{22}^{*} \geq q_{21}^{*}$ by considering the following two cases.

Case 1: $q_{22}>q_{c 1}$. Under this scenario, from Theorem 4.11, we easily have $q_{22}^{*}=q_{22}$ and $q_{22}^{*}>q_{c 1}$. Due to the fact that $q_{21}^{*}=\min \left\{\max \left\{q_{21}, 0\right\}, q_{c 1}\right\}$ in Theorem 4.9, we have $q_{c 1} \geq q_{21}^{*}$. Hence we have $q_{22}^{*} \geq q_{21}^{*}$.

Case 2: $q_{22} \leq q_{c 1}$. From Theorems 4.11 and 4.13, we have $q_{22}^{*}=q_{c 1} \geq q_{21}^{*}$ because of $q_{21}^{*}=\min \left\{\max \left\{q_{21}, 0\right\}, q_{c 1}\right\}$. Consequently, we have $q_{22}^{*} \geq q_{21}^{*}$.

On the other hand, by analyzing problems $P_{21}$ and $P_{22}$, we can obtain that the optimal robust profit of problem $P_{2}$ is equivalent to

$$
\begin{aligned}
\max _{q} \Pi_{2}^{F}(q) & =\max \left\{\max _{C^{F}(q) \leq K} \Pi_{21}^{F}(q), \max _{C^{F}(q) \geq K} \Pi_{22}^{F}(q)\right\} \\
& =\max \left\{\Pi_{21}^{F}\left(q_{21}^{*}\right), \Pi_{22}^{F}\left(q_{22}^{*}\right)\right\} .
\end{aligned}
$$

Then, from Theorems 4.11 and 4.13, we have

$$
q_{2}^{*}= \begin{cases}q_{21}^{*}, & \Pi_{21}^{F}\left(q_{21}^{*}\right) \geq \Pi_{22}^{F}\left(q_{22}^{*}\right), \\ q_{22}^{*}, & \Pi_{21}^{F}\left(q_{21}^{*}\right) \leq \Pi_{22}^{F}\left(q_{22}^{*}\right) .\end{cases}
$$

\section{References}

\section{References}

Avi-Yonah, R. S., \& Uhlmann, D. M. (2009). Combating global climate change: Why a carbon tax is a better response to global warming than cap and trade. Stanford Environmental Law Journal, 28(3), 3-50.

Alfares, H. K., \& Elmorra, H. H. (2005). The distribution-free newsboy problem: Extensions to the shortage penalty case. International Journal of Production Economics, 93-94, 465-477.

Andersson, J., Jörnsten, K., Nonås, S. L., Sandal, L., \& Ubøe, J. (2013). A maximum entropy approach to the newsvendor problem with partial information. European Journal of Operational Research, 228(1), 190-200.

Arikan, E., \& Jammernegg, W. (2014). The single period inventory model under dual sourcing and product carbon footprint constraint. International Journal of Production Economics, 157, 15-23.

Bertsimas, D., \& Thiele, A. (2006). A robust optimization approach to inventory theory. Operations Research, 54(1), 150-168.

Choi, T. M. (2013). Local sourcing and fashion quick response system: The impacts of carbon footprint tax. Transportation Research Part E, 55, 43-54. 
Dong, C. W., Shen, B., Chow, P. S., Yang, L., \& Ng, C. T. (2014). Sustainability investment under cap-and-trade regulation. Annals of Operations Research, doi: 10.1007/s10479-013-1514-1.

Du, S. F., Ma, F., Fu, Z., Zhu, L. L., \& Zhang, J. (2011). Game-theoretic analysis for an emission-dependent supply chain in a 'cap-and-trade' system. Annals of Operations Research, doi:10.1007/s10479-011-0964-6.

Du, S. F., Zhu, L. L., Liang, L., \& Ma, F. (2013). Emission-dependent supply chain and environment-policy-making in the 'cap-and-trade' system. Energy Policy, 57, 61-17.

Gallego, G., \& Moon, I. (1993). The distribution free newsboy problem: Review and extensions. Journal of the Operational Research Society, 44(8), 825-834.

Gong, X. T., Zhou, S. X. (2013). Optimal production planning with emissions trading. Operations Research, 61(4), 908-924.

Güray Güler, M. (2014). A note on: 'The effect of advertising on the distribution-free newsboy problem'. International Journal of Production Economics, 148, 90-92.

Han, Q. M., Du, D. L., \& Zuluaga, Z. L. (2014). A risk- and ambiguity-averse extension of the max-min newsvendor order formula. Operations Research, 62(3), 535-542.

He, Y. Y., Wang, L. Z., \& Wang, J. H. (2012). Cap-and-trade vs. carbon taxes: A quantitative comparison from a generation expansion planning perspective. Computers \& Industrial Engineering, 63(3), 708-716.

Kamburowski, J. (2014). The distribution-free newsboy problem under the worst-case and best-case scenarios. European Journal of Operational Research, 237(1), 106-122.

Kevork, I. S. (2010). Estimating the optimal order quantity and the maximum expected profit for single-period inventory decisions. Omega, 38(3-4), 218-227.

Khouja, M. (1996). A note on the newsboy problem with an emergencey supply option. Journal of Operational Research Society, 47(12), 15301534.

Kumar, R. S., \& Goswami, A. (2015). A continuous review production-inventory system in fuzzy random environment: Minmax distribution free procedure. Computer E Industrial Engineering, 79, 65-75.

Lan, Y. J., Ball, M. O. \& Karaesmen, I. Z. (2011). Regret in overbooking and fare-class allocation for single leg. Manufacturing \& Service Operations Managemetn, 13(2), 194-208.

Lee, C. M., \& Hsu, S. L. (2011). The effect of advertising on the distribution-free newsboy problem. International Journal of Production Economics, 129(1), 217-224.

Liao, Y., Banerjee, A., \& Yan, C. Y. (2011). A distribution-free newsvendor model with balking and lost sales penalty. International Journal of Production Economics, 133(1), 224-227.

Liu, B. Y., Holmbom, M., Segerstedt, A., \& Chen, W. D. (2015). Effects of carbon emission regulations on remanufacturing decisions with limited information of demand distribution. International Journal of Production Research, 53(2), 532-548.

Manikas, A. S., Kroes, J. R. (2015). A newsvendor approach to compliance and production under cap and trade emissions regulation. International Journal of Production Economics, 159, 274-284.

Moon, I., \& Choi, S. (1995). The distribution free newsboy problem with balking. Journal of Operational Research Society, 46(4), 537-542.

Mostard, J., De Koster, R.,\& Teunter, R. (2005). The distribution-free newsboy problem with resalable returns. International Journal of Production Economics, 97(3), 329-342.

Oberlaender, M. (2011). Dual sourcing of a newsvendor with exponential utility of profit. International Journal of Production Economics, 133(1), 370-376.

Ouyang, L. Y., \& Chang, H. C. (2002). A minimax distribution free procedure for mixed inventory models involving variable lead time with fuzzy lost sales. International Journal of Production Economics, 76(1), 1-12.

Pando, V., San-José, L. A., García-Laguna, J., \& Sicilia, J. (2013). A newsboy problem with an emergency order under a general backorder rate function. Omega, 41, 1020-1028.

Perakis, G., \& Roels, G. (2008). Regret in the newsvendor model with partial information. Operations Research, 56(1), 188-203.

Rosič, H., \& Jammernegg, W. (2013). The economic and environmental performance of dual sourcing: A newsvendor approach. International Journal of Production Economics, 143(1), 109-119.

Scarf, H. E. (1958). A min-max solution of an inventory problem. Arrow K J, Karlin S, Scarf H E. Studies in the Mathematical Theory of Inventory and Production. Stanford University Press.

Song, J. P., \& Leng, M. M. (2012). Analysis of the single-period problem under carbon emissions policies. In Handbook of newsvendor Problems. International Series in Operations Research and Management Science, Edited by T.-M. Choi, Vol. 176, 297-313. NewYork: Springer

Warburton, R. D. H., \& Stratton, R. (2005). The optimal quantity of quick response manufacturing for an onshore and offshore sourcing model. International Journal of Logistics: Research and Applications, 8(2), 125-141.

World Bank. (2014). State and Trends of Carbon Pricing. World Bank Group. Available at https://openknowledge.worldbank.org/handle/10986/18415, accessed on August 23, 2014.

Yue, J. F., Chen, B. T., \& Wang, M. C. (2006). Expected value of distribution information for the newsvendor problem. Operations Research, 54(6), $1128-1136$.

Zhang, B., \& Xu, L. (2013). Multi-item production planning with carbon cap and trade mechanism. International Journal of Production Economics, $144(1), 118-127$.

Zhu, Z. S., Zhang, J. W., \& Ye, Y. Y. (2013). Newsvendor optimization with limited distribution information. Optimization Methods \& Software, 28(3), 640-667. 
List of table and figure captions

Table 1. The major parameters and notations in this paper

Table 2. The computational results for the Example with different values of $\sigma$

Figure 1. Graphical representation of the newsvendor problem with dual sourcing

Figure 2. Effects of $c_{t}$ under carbon tax regulation

Figure 3. Effects of $K$ under cap-and-trade regulation

Figure 4. Effects of $c_{b}$ under cap-and-trade regulation

Figure 5. Effects of $c_{s}$ under cap-and-trade regulation 
Table 1. The major parameters and notations in this paper

\begin{tabular}{cl}
\hline Parameters & Unit selling price \\
$p$ & Unit cost from the offshore supplier \\
$c$ & Unit salvage price \\
$a$ & Second order premium per unit, i.e., unit ordering cost from the onshore supplier is $c+a$ \\
$d$ & Market demand, which is assumed to be a random \\
$\mu$ & Expected demand \\
$\sigma$ & Standard deviation of the demand \\
$F$ & Distribution of $d$, which partial information including $u$ and $\sigma$ are known \\
$\Psi$ & Set of cumulative distribution functions with mean $u$ and variance $\sigma^{2}$ \\
$e_{1}$ & Amount of carbon emission per unit generated from the first order \\
$e_{2}$ & Amount of carbon emission per unit generated from the leftover inventory \\
$e_{3}$ & Amount of carbon emission per unit generated from the second order \\
$K$ & Carbon emission cap \\
$c_{b}$ & Unit buying price of carbon emission permit under cap-and-trade regulation \\
$c_{s}$ & Unit selling price of carbon emission permit under cap-and-trade regulation \\
$c_{t}$ & Unit tax paid by the retailer for each unit of emission \\
Others & \\
$P_{0}$ & Newsvendor problem with dual sourcing without carbon emission consideration \\
$P_{1}$ & Newsvendor problem with dual sourcing under carbon tax regulation \\
$P_{2}$ & Newsvendor problem with dual sourcing under cap-and-trade regulation \\
$q$ & Order quantity from the offshore supplier \\
Decision variables & \\
Objective functions & Expected profit for problem $P_{0}$ \\
$\Pi_{0}(q)$ & Expected profit for problem $P_{1}$ \\
$\Pi_{1}(q)$ & Expected profit for problem $P_{2}$ \\
$\Pi_{2}(q)$ & Expected carbon emission level/amount \\
$C(q)$ &
\end{tabular}

Table 2. The computational results for the Example with different values of $\sigma$

\begin{tabular}{ccccccc}
\hline$\sigma$ & $q_{1}^{*}$ & $\Pi_{1}^{F}\left(q_{1}^{*}\right)$ & $C^{F}\left(q_{1}^{*}\right)$ & $q_{2}^{*}$ & $\Pi_{2}^{F}\left(q_{2}^{*}\right)$ & $C^{F}\left(q_{2}^{*}\right)$ \\
\hline 98 & 701.33 & $2.5964 \times 10^{4}$ & 3686.1 & 762.81 & $4.058 \times 10^{4}$ & 3986.5 \\
196.5 & 602.17 & $2.4721 \times 10^{4}$ & 3370.7 & 725.42 & $3.9152 \times 10^{4}$ & 3972.9 \\
294 & 504.00 & $2.3491 \times 10^{4}$ & 3058.4 & 688.42 & $3.774 \times 10^{4}$ & 3959.4 \\
392 & 405.35 & $2.2255 \times 10^{4}$ & 2744.5 & 651.22 & $3.6319 \times 10^{4}$ & 3945.9 \\
980 & 0 & $1.4715 \times 10^{4}$ & 1730.0 & 428.06 & $2.7798 \times 10^{4}$ & 3864.7 \\
\hline
\end{tabular}




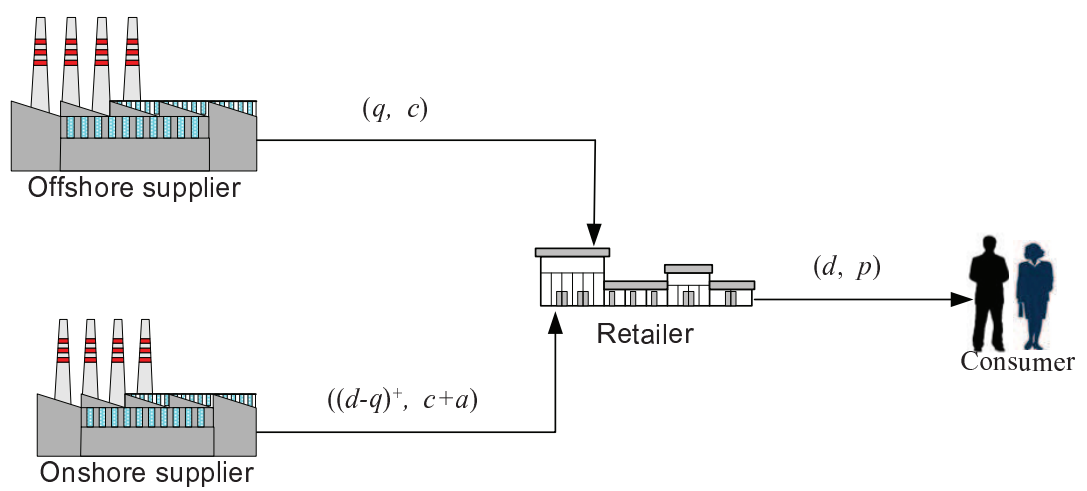

Figure 1: Graphical representation of the newsvendor problem with dual sourcing

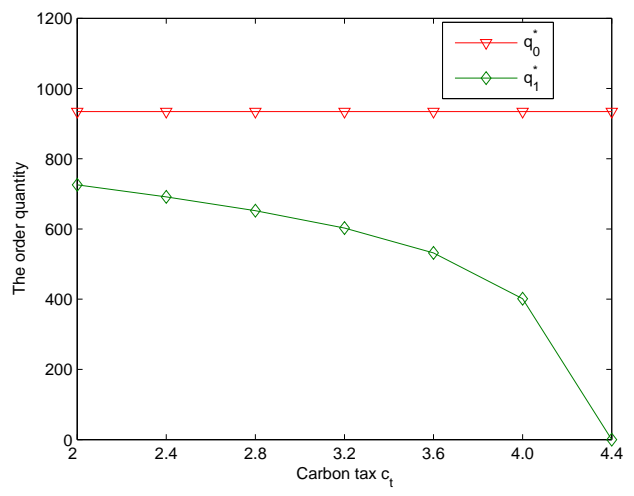

(a) Effects of $c_{t}$ on $q_{1}^{*}$

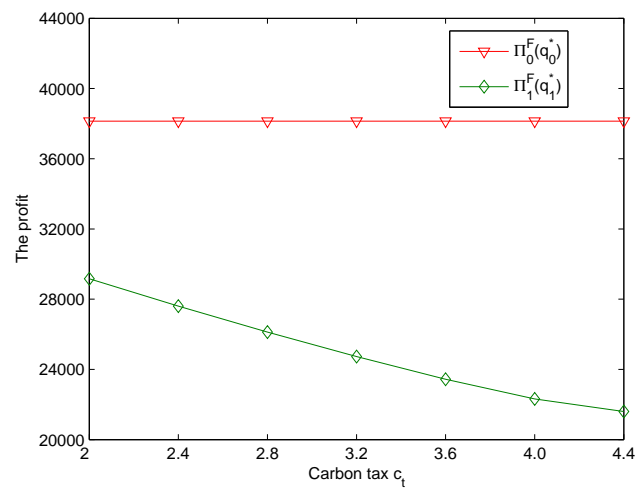

(b) Effects of $c_{t}$ on $\Pi_{1}^{F}\left(q_{1}^{*}\right)$

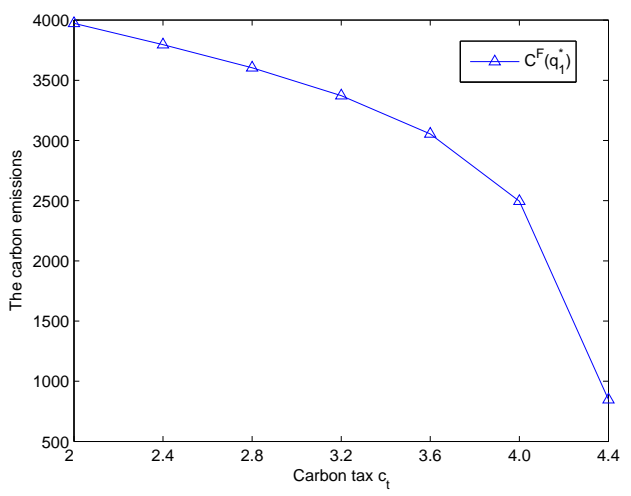

(c) Effects of $c_{t}$ on $C^{F}\left(q_{1}^{*}\right)$

Figure 2: Effects of $c_{t}$ under carbon tax regulation 


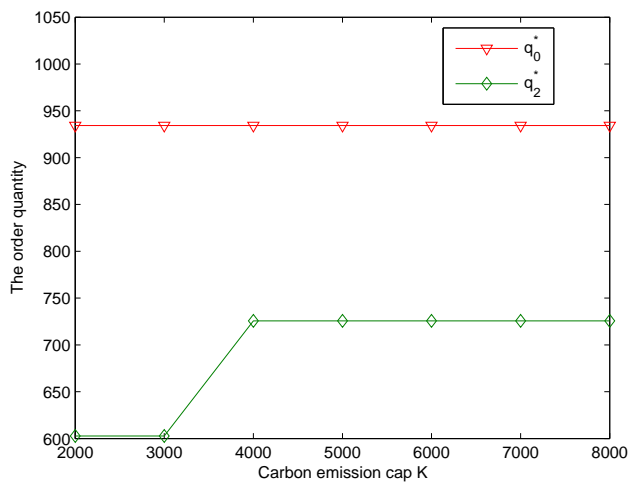

(a) Effects of $K$ on $q_{2}^{*}$

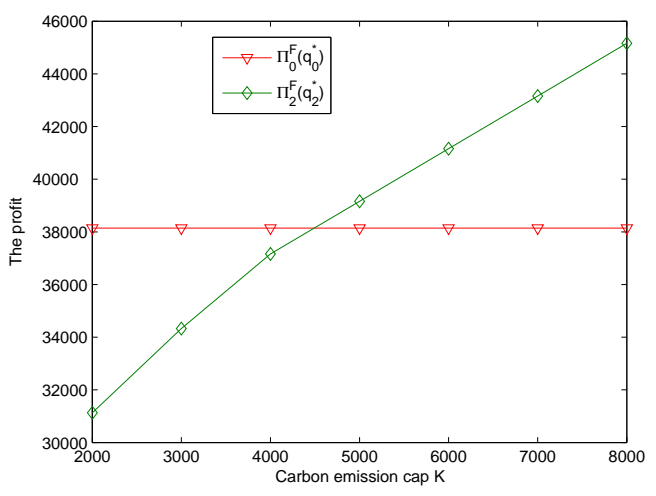

(b) Effects of $K$ on $\Pi_{2}^{F}\left(q_{2}^{*}\right)$

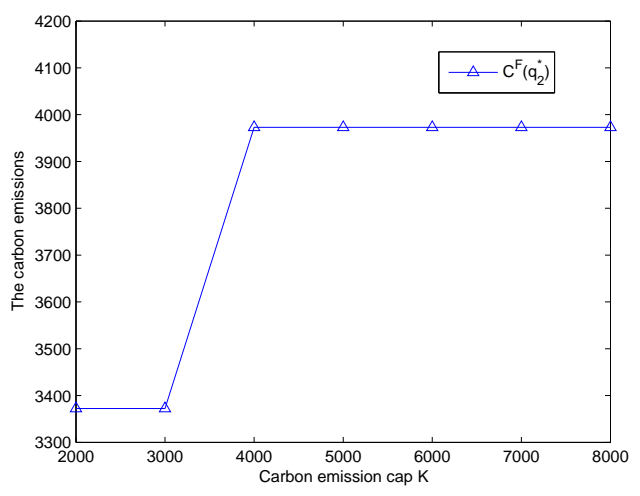

(c) Effects of $K$ on $C^{F}\left(q_{2}^{*}\right)$

Figure 3: Effects of $K$ under cap-and-trade regulation 


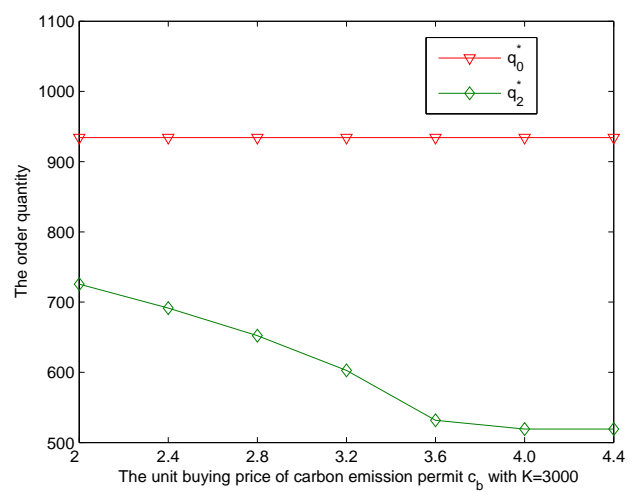

(a) Effects of $c_{b}$ on $q_{2}^{*}$

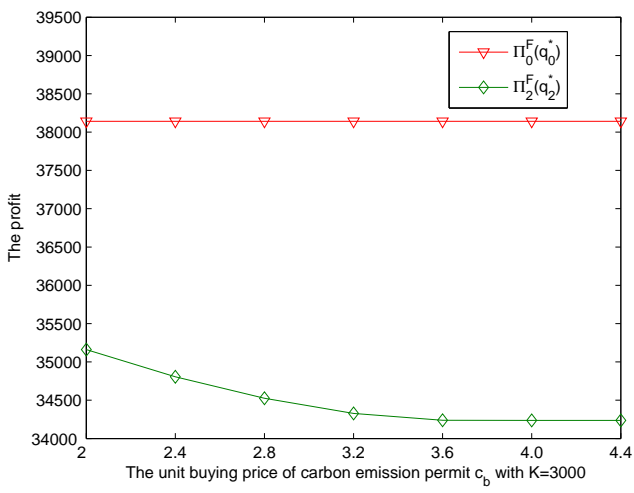

(b) Effects of $c_{b}$ on $\Pi_{2}^{F}\left(q_{2}^{*}\right)$

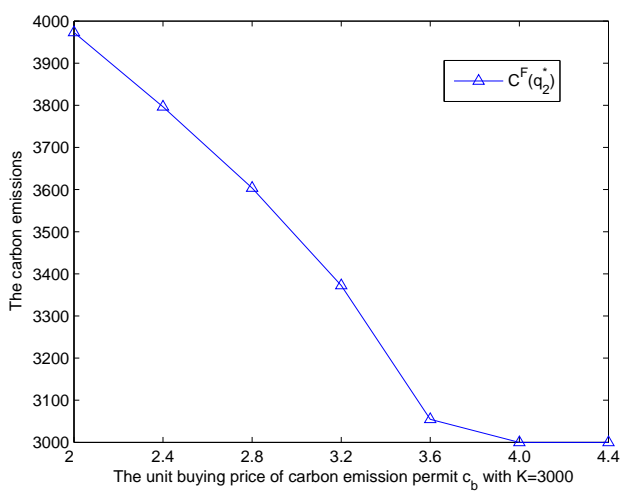

(c) Effects of $c_{b}$ on $C^{F}\left(q_{2}^{*}\right)$

Figure 4: Effects of $c_{b}$ under cap-and-trade regulation 


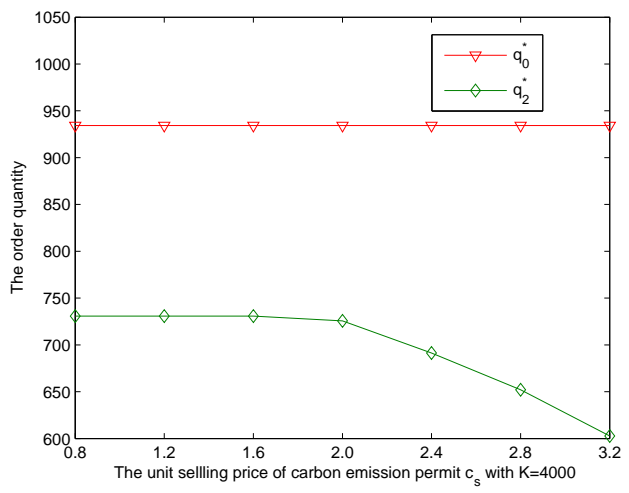

(a) Effects of $c_{s}$ on $q_{2}^{*}$

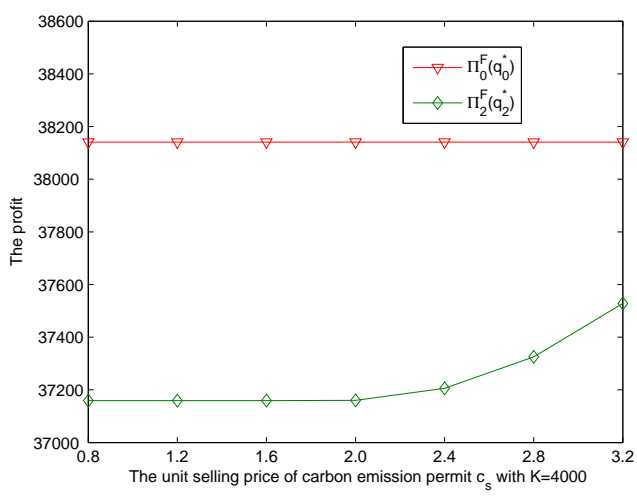

(b) Effects of $c_{s}$ on $\Pi_{2}^{F}\left(q_{2}^{*}\right)$

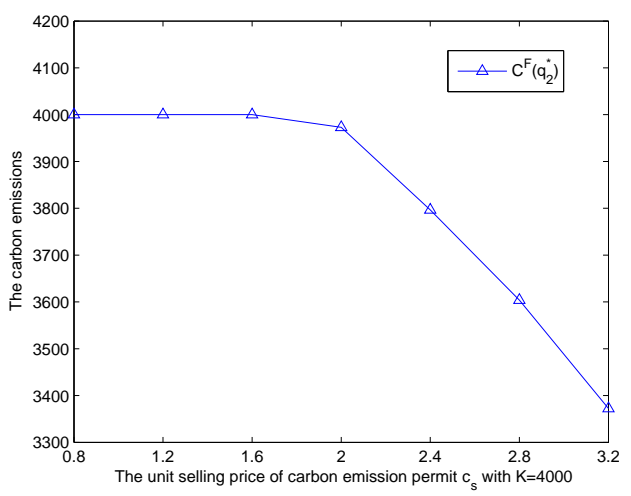

(c) Effects of $c_{s}$ on $C^{F}\left(q_{2}^{*}\right)$

Figure 5: Effects of $c_{s}$ under cap-and-trade regulation 